Article

\title{
Silver Nanoparticle Arrays onto Glass Substrates Obtained by Solid-State Thermal Dewetting: A Morphological, Structural and Surface Chemical Study
}

\author{
Juan Agustín Badán ${ }^{1}$, Elena Navarrete-Astorga ${ }^{2}$, Rodrigo Henríquez ${ }^{3}$, Francisco Martín Jiménez ${ }^{2}$, \\ Daniel Ariosa ${ }^{1}$, José Ramón Ramos-Barrado ${ }^{2}$ and Enrique A. Dalchiele ${ }^{1, *}$
}

1 Instituto de Física, Facultad de Ingeniería, Universidad de la República, Julio Herrera y Reissig 565, C.C. 30 , Montevideo 11000, Uruguay; abadan@fing.edu.uy (J.A.B.); dariosa@fing.edu.uy (D.A.)

2 Laboratorio de Materiales y Superficies (Unidad Asociada al CSIC), Departamentos de Física Aplicada \& Ing. Química, Universidad de Málaga, E29071 Málaga, Spain; enavarrete@uma.es (E.N.-A.); marjim@uma.es (F.M.J.); barrado@uma.es (J.R.R.-B.)

3 Instituto de Química, Facultad de Ciencias, Pontificia Universidad Católica de Valparaíso, Av. Brasil, Valparaíso 2950, Chile; rodrigo.henriquez@pucv.cl

* Correspondence: dalchiel@fing.edu.uy; Tel.: +598-27142714

Citation: Badán, J.A.;

Navarrete-Astorga, E.; Henríquez, R.;

Jiménez, F.M.; Ariosa, D.;

Ramos-Barrado, J.R.; Dalchiele, E.A Silver Nanoparticle Arrays onto Glass Substrates Obtained by Solid-State Thermal Dewetting: A

Morphological, Structural and

Surface Chemical Study.

Nanomaterials 2022, 12, 617. https:// doi.org/10.3390/nano12040617

Academic Editor: Cinzia Sada

Received: 20 January 2022

Accepted: 3 February 2022

Published: 11 February 2022

Publisher's Note: MDPI stays neutral with regard to jurisdictional claims in published maps and institutional affiliations.

Copyright: (C) 2022 by the authors. Licensee MDPI, Basel, Switzerland. This article is an open access article distributed under the terms and conditions of the Creative Commons Attribution (CC BY) license (https:// creativecommons.org/licenses/by/ $4.0 /)$.

\begin{abstract}
Silver nanoparticles (NPs) on glass substrates were obtained by a solid-state thermal dewetting (SSD) process using vacuum-evaporated-silver precursor layers. An exhaustive investigation of the morphological, structural, and surface chemistry properties by systematically controlling the precursor film thickness, annealing temperature, and time was conducted. Thin silver films with thicknesses of 40 and $80 \mathrm{~nm}$ were deposited and annealed in air by applying a combined heat-up+constant temperature-time program. Temperatures from 300 to $500{ }^{\circ} \mathrm{C}$ and times from 0 to 50 min were assayed. SSD promoted the morphological modification of the films, leading to the Ag NPs having a discrete structure. The size, shape, surface density, and inter-nanoparticle distance of the nanoparticles depended on the initial film thickness, annealing temperature, and time, exhibiting a cubic silver structure with a (111) preferred crystallographic orientation. The prepared NPs were found to be highly enriched in the $\mathrm{Ag}\{111\} / \operatorname{Ag}\{110\} / \operatorname{Ag}\{100\}$ equilibrium facets. SSD not only promotes NP formation but also promotes the partial oxidation from $\mathrm{Ag}$ to $\mathrm{AgO}$ at the surface level. $\mathrm{AgO}$ was detected on the surface around the nanoparticles synthesized at $500{ }^{\circ} \mathrm{C}$. Overall, a broad framework has been established that connects process factors to distinguish resultant Ag NP features in order to develop unique silver nanoparticles for specific applications.
\end{abstract}

Keywords: silver; nanoparticles; solid state dewetting; nanostructured layers; facets

\section{Introduction}

Noble metallic nanoparticles ( $\mathrm{Au}, \mathrm{Pt}, \mathrm{Ag})(\mathrm{NPs})$ have attracted a great deal of attention due to their unique physical features and interesting electrochemical and mechanical properties [1-6]. In particular, their optical properties, which have been known since antiquity, have already proven a fraction of their potential, and further major discoveries should be expected in the future [2,7-9]. In fact, one of the most important properties of such nanoparticles is the result of the interaction of these metallic nanostructures with incident light, generating collective oscillation modes of the conduction electrons in the particles, called plasmons, which become dominant and produce the surface plasmon resonance (SPR), resulting in the appearance of an electromagnetic field that is localized on the NPs [6,7,9-12]. The localized surface plasmon resonance (LSPR) phenomenon arises when the oscillations of the electromagnetic field of an incoming electromagnetic wave are in resonance with those of the local electromagnetic field of the NPs, which is defined by the resonance oscillation frequencies (both in the visible and near-infrared 
ranges., i.e., 400-1000 nm) [7-9,13]. More importantly, the resonant wavelengths of the LSPR can be tuned through the shape, size, uniformity, density, spacing, arrangement, type of the metallic nanoparticles, and their environment $[2,6,7,9,10,13]$. Furthermore, the physico-chemical characteristics of noble metallic NPs may be tailored extensively by manipulating their size and shape, which is a critical problem for a variety of technological applications [2,4]. LSPR also boosts Raman and fluorescence signals by creating large field enhancement [2,7]. As a result, noble metal nanoparticles have been rapidly produced for applications such as surface-enhanced Raman scattering (SERS) [14,15]. Due to their unique optical properties, the noble metallic nanoparticles detailed and discussed above have been intensively employed in a broad range of applications in the biomedical (bioimaging, biosensing, nanosurgery, drug delivery, photothermal therapy), energy, catalysis, and information technology (data storage) fields [2,7]. The development of single-molecule analytical systems has received a lot of interest in recent years; as a result, innovative sensing technologies based on localized surface plasmons in metallic nanoparticles have received a lot of attention (i.e., single-molecule sensing by fluorescence enhancement and plasmon shifts) $[9,16]$.

Because of its strong resonance and low optical losses in the visible and near infrared parts of the spectrum, Ag, a cost-effective noble metal, has been frequently employed among many metallic NPs [2,17-20]. For instance, when designing plasmon-enhanced solar cells, Ag NPs are preferred over Au NPs because Ag NPs provide significantly larger path length increases [19,21]. As a result, Ag NPs are now employed in a variety of applications due to their distinctive physical, chemical, electrical, and size-dependent optical capabilities; Ag NPs have been used in the following applications: targeted drug delivery, wastewater treatment, biosensors, antimicrobial activity, solar cells, photo catalysis, and catalytic activity as well as for the detection of chemical species via SERS $[2,5,10,20]$.

Thus, in the context of the huge developments that have been made in noble metallic nanoparticle application areas in recent years, several methods for silver nanoparticle synthesis have been described $[5,22,23]$. Chemical and electrochemical techniques, thermal breakdown, microwave synthesis, sonochemical synthesis, microemulsion synthesis, solvothermal synthesis, co-precipitation, and photoreduction have all been employed in the fabrication of Ag NPs [5,22-24]. Although most of these chemical and physical methods produce Ag NPs of good quality (desired shape and size), some of these methods synthesize these nanoparticles in a liquid phase, and the Ag NPs that are prepared remain in the form of colloidal solutions [5,10,22-25].

However, in many emerging nanoelectronic and optoelectronic technologies and applications, such as nanophotonic devices, new-generation solar cells, magnetic recording, sensors, and plasmonics, patterning metallic nanoparticles onto a substrate surface is desired [1,13,25-29], which, in the case of Ag NP colloidal solutions, the organization of the synthesized nanoparticles is difficult to control, and periodic arrays are challenging to realize $[1,25,27]$. In particular, the structure and properties of the metal nanostructures placed on nonmetal surfaces are of tremendous interest due to their potential use in different electronic, magnetic, and optical devices [30]. As a result, the development of simple, multipurpose, and low-cost methodologies for fabricating metallic nanoparticle arrays with the desired shape, size, and arrangement directly onto a solid substrate surface is the main critical issue for the use of metal nanostructures in order to make solid-state technological applications possible [4,28,31,32]. Moreover, and very importantly, in order to ensure the desired control of nanostructures, it is critical to have a thorough understanding of the fundamental microscopic mechanisms that govern the processes used in these approaches $[4,28,31,32]$. Several techniques have been reported for the production of microand nanoscale metallic particles arrays supported onto a solid substrate, including spray pyrolysis [33,34], sol-gel [35], electroless metal deposition [34], electrodeposition [34], and solid-state dewetting (SSD) [4,25,36-40].

Solid-state dewetting is a simple, low-cost, and industrially known scalable approach for the fabrication of substrate-bound metallic nanoparticles arrays onto various substrates, 
including glass, $\alpha-\mathrm{Fe}_{2} \mathrm{O}_{3}(0001) / \alpha-\mathrm{Al}_{2} \mathrm{O}_{3}(0001), \alpha-\mathrm{Fe}_{2} \mathrm{O}_{3}(0001) / \mathrm{SrTiO}_{3}(111)$, and ceramic single-crystals such as $c$-plane sapphire $\left(\alpha-\mathrm{Al}_{2} \mathrm{O}_{3}\right)$ and silicon [38,41-44]; in recent years, it has received a lot of interest as a viable approach for the large-scale fabrication of advanced photonic nanostructures $[25,28,41,45-47]$. SSD is a spontaneous phenomenon where a continuous polycrystalline metallic thin film onto a surface rearranges itself into an ensemble of separated islands or droplets upon appropriate annealing [25,28,41,45-48]. The original continuous film breaks apart into numerous particles in the same way as a water layer would on a hydrophobic surface, and this process is known as dewetting [25,28,41,45-48]. The SSD process can be induced by thermal annealing [12,26,31,36,38,40,41,49], pulsed laser heating $[1,4,39,50]$, combined thermal annealing and pulsed laser heating [27], ion beam irradiation [51-54], electron beam irradiation [55], and inductively coupled plasma discharge [56]. Nonetheless, thermal annealing is probably the simplest way to promote dewetting, particularly when working on large areas. Deposited metallic films with thickness of a few nanometers are defective metastable layers that are comprised of polycrystalline grains (formed in a Volmer-Wever growth mode) with nanoscale islands that strain toward each other as they merge $[25,28,41,46,47,57,58]$. Then, dewetting can occur at temperatures considerably below the melting point of the material, highlighting the island structure, which appears in the initial pristine polycrystalline precursor film [25,28,41,46,47,57]. The main driving force for SSD is the reduction in the total free energy at the interfaces between the air, film, and substrate, which occurs via diffusive mass transfer at the surface, interface, or grain boundaries $[25,28,41,45-48,59]$. Thus, controlling the SSD process parameters in a precise way creates the possibility of obtaining nano-objects with a pre-defined statistical size and spatial distribution (starting from a thin polycrystalline metallic film), avoiding complicated and expensive lithographical subtractive processes $[28,46]$.

In this work, silver nanoparticle arrays onto glass substrates are obtained by a solidstate thermal dewetting process using vacuum-evaporated polycrystalline silver precursor layers. An exhaustive investigation of the morphological, structural, and surface chemistry properties by means of the systematic control of the precursor film thickness, annealing temperature, and time is carried out.

\section{Materials and Methods}

\subsection{Preparation of the Silver Nanoparticle Arrays onto Glass Substrates by Solid-State Dewetting}

Plain soda lime glass microscope slide substrates that were $75 \times 25 \mathrm{~mm}^{2}$ in size were used. First, they have were cut into smaller rectangles that were $2 \mathrm{~cm}^{2}$ in size. Further and prior to deposition, these glass substrates were submitted to ultrasonic cleaning with acetone, isopropanol, and water, with the samples being placed in each solution for $15 \mathrm{~min}$. They were then dried with a dry air flux.

After, a silver layer with a controlled thickness (nominal thickness, $\mathrm{d}_{\mathrm{Ag}}$ ) was deposited onto these cleaned glass substrates by vacuum thermal evaporation at a high vacuum rate with $\sim 10^{-6}$ Torr of base pressure (Intercorvamex, México City, México); Ag pellets with a purity of $99.99 \%$ were used (Aldrich, St. Louis, MO, USA). The deposition rate was optimized at 1-2.5 $\AA$ /s to grow good-quality uniform films. The thicknesses of these films were monitored using an INFICON front load single sensor with a quartz crystal. This was connected to an INFICON STM-2 USB thin film rate/thickness monitor. The post-deposition annealing process to trigger solid-sate dewetting was performed in a quartz tube furnace at a temperature $\mathrm{T}_{\mathrm{A}}$ for an annealing time $\mathrm{t}_{\mathrm{A}}$.

\subsection{Morphological and Structural Characterization}

Field-emission scanning electron microscopy (FE-SEM) pictures of the Ag NPs that formed on the glass substrate surface were obtained on a Helios Nanolab 650 Dual Beam from FEI equipment company. These FE-SEM images were taken under the following conditions: $2 \mathrm{kV}$ and $100 \mathrm{pA}$ for the operating voltage and current, respectively; in Mode II, immersion was determined through the lens detector. 
The surface morphology of the deposits was examined using an atomic force microscope (AFM). Topographic AFM examinations were performed using a Nanoscope V tapping-mode AFM (Veeco Instruments, Plainview, NY, USA) by employing sharp silicon tips.

Transmission electron microscopy (TEM), high-resolution transmission electron microscopy (HRTEM), and selected-area electron diffraction (SAED) were carried out with a Philips CM-200 microscope operated at $200 \mathrm{kV}$ to obtain the orientation of the crystalline plane, crystal size, and the distance between them.

The structural characterization of the sample was determined by X-ray diffraction (XRD) by using a PANalytical X'Pert PRO MRD diffractometer and a PANalytical PW3050/65 (Theta/2Theta) goniometer. X-ray source: sealed tube, ceramic $\mathrm{Cu}$ Anode.

The FE-SEM images were studied using Image J software to obtain the size distributions, circularity, and autocorrelation functions of the Ag NPs on each sample. In the case of the AFM images, they were analyzed using Gwyddion software.

Circularity $C$ was calculated using Image J software. Using ellipse fits, the area and perimeter of each NP were obtained. Subsequently $C$ was calculated as the mean value of $\frac{4 \pi * \text { area }}{\text { perimeter }^{2}}$.

\subsection{Surface Chemistry Analysis}

X-ray photoelectron spectroscopy XPS was carried out with a Versaprobe II equipment with a focused monochromatic Al K $\alpha$ X-ray source $(1486.6 \mathrm{eV})$ and a Physical Electronics PHI 5700XPS with $\mathrm{Mg} \mathrm{K} \alpha(1253.6 \mathrm{eV})$ radiation, both of which were from Physical Electronics PHI, Chanhassen, MN, USA. The binding energies were corrected against to determine $\mathrm{C}$ at a $1 \mathrm{~s}$ peak of adventitious carbon fixed at $284.8 \mathrm{eV}$. The samples were analysed as obtained, and they were later etched with $4 \mathrm{KeV} \mathrm{Ar}^{+}$ions for $1 \mathrm{~min}$.

\section{Results and Discussion}

\subsection{Synthesis of the Ag Nanoparticle Arrays onto Glass Substrates}

Silver nanoparticle (NP) arrays were formed on the glass surface through the solidstate dewetting (SSD) process, which consists of two steps: (i) a precursor silver layer is deposited onto glass substrates, and (ii) these samples are then submitted to an annealing treatment to trigger the actual solid-state dewetting process. Starting film thickness, initial film crystallographic orientation, annealing temperature, annealing duration, and annealing environment are the key factors of the film and process that determine nanoparticle formation and the final morphology and size of the nanoparticles $[28,47,60]$. In the present case, all of the above-mentioned critical enumerated parameters: the thickness of the initial silver layer $\left(\mathrm{d}_{\mathrm{Ag}}\right)$, annealing temperature $\left(\mathrm{T}_{\mathrm{A}}\right)$, and the annealing time $\left(\mathrm{t}_{\mathrm{A}}\right)$, have been taken into consideration as variable parameters. Figure 1 depicts the temperature-time profile program of the annealing step of the solid-state dewetting process employed in present study. In an attempt to experimentally uncouple the effects of temperature and time on the SSD mechanism, this temperature-time profile program was employed. In the diagram below, two different zones can be identified: the heat-up region (temperature-time ramp) and the constant temperature region (temperature-time plateau).

The first test allowed us to study increases in the annealing temperature and the evolution of the precursor silver thin films (for different $\mathrm{d}_{\mathrm{Ag}}$ values) during the formation of the Ag NPs during this step of the SSD process (allowing for more accurate thermodynamic data). The second experiment allowed us to study the effect of the annealing time at different $T_{A}$ values and for different $d_{A g}$ values during the formation of the $\mathrm{Ag}$ NPs during this step of the SSD process (allowing for more accurate kinetic data). Dewetting is usually noticed at a specific temperature, $\mathrm{T}_{\text {dewet }}$, which depends on the metal and on its thickness [47]. In the case of silver layers with thickness values of $20 \mathrm{~nm}$ to $80 \mathrm{~nm}$, the $\mathrm{T}_{\text {dewett }}$ value is between $300{ }^{\circ} \mathrm{C}$ and $500{ }^{\circ} \mathrm{C}$ (well below its melting temperature $\mathrm{T}_{\mathrm{m}}=961^{\circ} \mathrm{C}$ ) $[47,61]$. Because of this, in present study, based both on this $\mathrm{T}_{\text {dewett }}$ value and the mechanical stability of glass substrates (whose transformation temperature is $525^{\circ} \mathrm{C}$ ), 
the maximum studied temperature was $500{ }^{\circ} \mathrm{C}$. In both study cases (temperature-time ramp and temperature-time plateau), the natural cooling of the samples until they reached room temperature was applied as part of the experimental protocol.

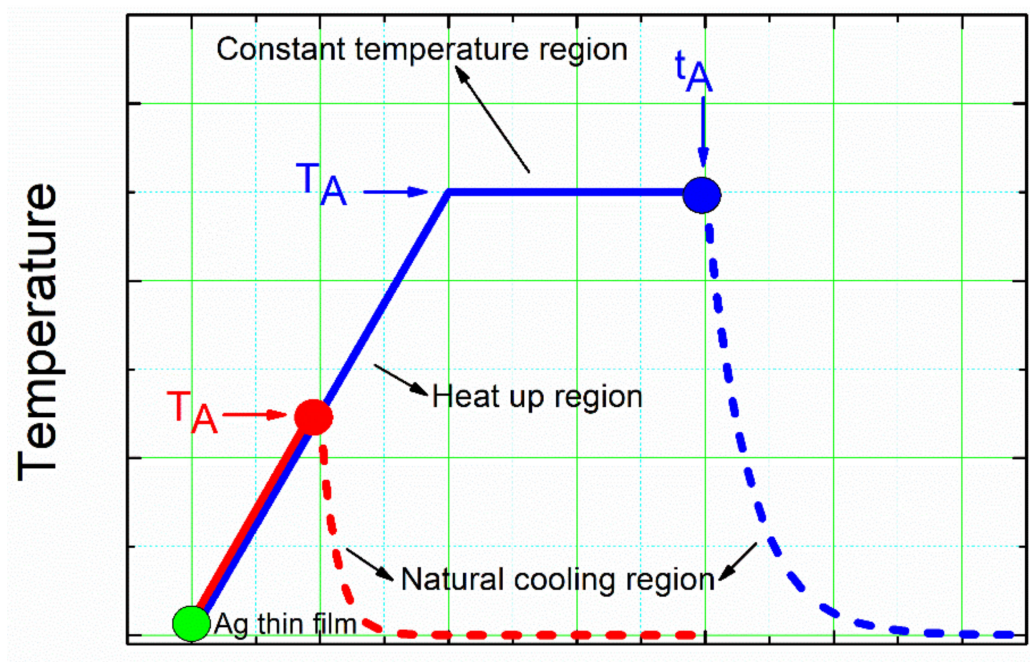

Time

Figure 1. Schematic diagram of the temperature-time profile program employed for the annealing step of the solid-state dewetting process, where the different annealing and cooling to room temperature regions are indicated. Red and blue areas were used to determine the effects of the annealing temperature $\left(\mathrm{T}_{\mathrm{A}}\right)$ and the annealing time $\left(\mathrm{t}_{\mathrm{A}}\right)$, respectively, on the morphological and structural properties of the resulting silver nanoparticles/glass substrate samples.

\subsection{Morphological Characterization of the Ag Nanoparticle Arrays}

As mentioned above, the first step in the SSD process is the deposition of a precursor silver layer onto the glass substrates via vacuum thermal evaporation. In the present work, two different silver layer thickness $d_{A g}$ were studied, i.e., $d_{A g}=40 \mathrm{~nm}$ and $80 \mathrm{~nm}$. Figure 2 shows representative 2D and 3D AFM images of these silver layers, which show the surface aspects and the morphological characteristics. AFM analysis was limited to smaller areas $(1 \mu \mathrm{m} \times 1 \mu \mathrm{m})$ that were randomly chosen on the substrates to provide a better morphological characterization of the silver precursor layers. In the case of a silver layer with $d_{A g}=40 \mathrm{~nm}$, a rough dome-shaped nanostructured surface with a surface roughness value (RMS) of $6.1 \mathrm{~nm}$ can be seen, whereas for the thicker silver layers $\left(\mathrm{d}_{\mathrm{Ag}}=80 \mathrm{~nm}\right)$, a dome-shaped nanostructure with a rougher surface can be appreciated with a surface roughness value RMS $=11.6 \mathrm{~nm}$, as shown by the cross-sectional line profiles in Figure 2 . The last step of the Volmer-Weber growth process for metal thin films on a glass substrate is characterized by these rough granular morphologies [31]. Figure 2 shows that in the case of a silver layer with $\mathrm{d}_{\mathrm{Ag}}=40 \mathrm{~nm}$, the silver nanoparticles exhibited a mean size of $42 \mathrm{~nm}$, and some isolated areas with higher height values with respect to the whole inspected surface are depicted; whereas for the thicker layers $\left(\mathrm{d}_{\mathrm{Ag}}=80 \mathrm{~nm}\right)$, the silver nanoparticles with a mean size of $56 \mathrm{~nm}$ are dispersed and have a more homogeneous height distribution.

Figures $3 \mathrm{a}$ and $4 \mathrm{a}$ show FE-SEM micrographs of as-grown precursor silver thin films with thicknesses of $d_{A g}=40 \mathrm{~nm}$ and $d_{A g}=80 \mathrm{~nm}$, respectively, deposited on a glass substrate via vacuum thermal evaporation. Well-covered and continuous layers can be observed. Figures $3 \mathrm{~b}-\mathrm{f}$ and $4 \mathrm{~b}-\mathrm{f}$ show FE-SEM micrograph images of vacuum-thermalevaporated silver layers with nominal thicknesses $d_{A g}=40 \mathrm{~nm}$ and $d_{A g}=80 \mathrm{~nm}$, respectively, at different stages of the annealing step during the SSD process applying the heat-up region program depicted in Figure 1 and ending at different $T_{A}$ values, as indicated; this demonstrates that the silver thin films undergo a transition from continuous to discontinuous as exposure to the glass substrate increases. At a first glance, the FE-SEM micrographs illustrate that annealing at lower temperatures produces larger, elongated silver 
particles than annealing at higher temperatures, which produces smaller, more spherical silver particles.
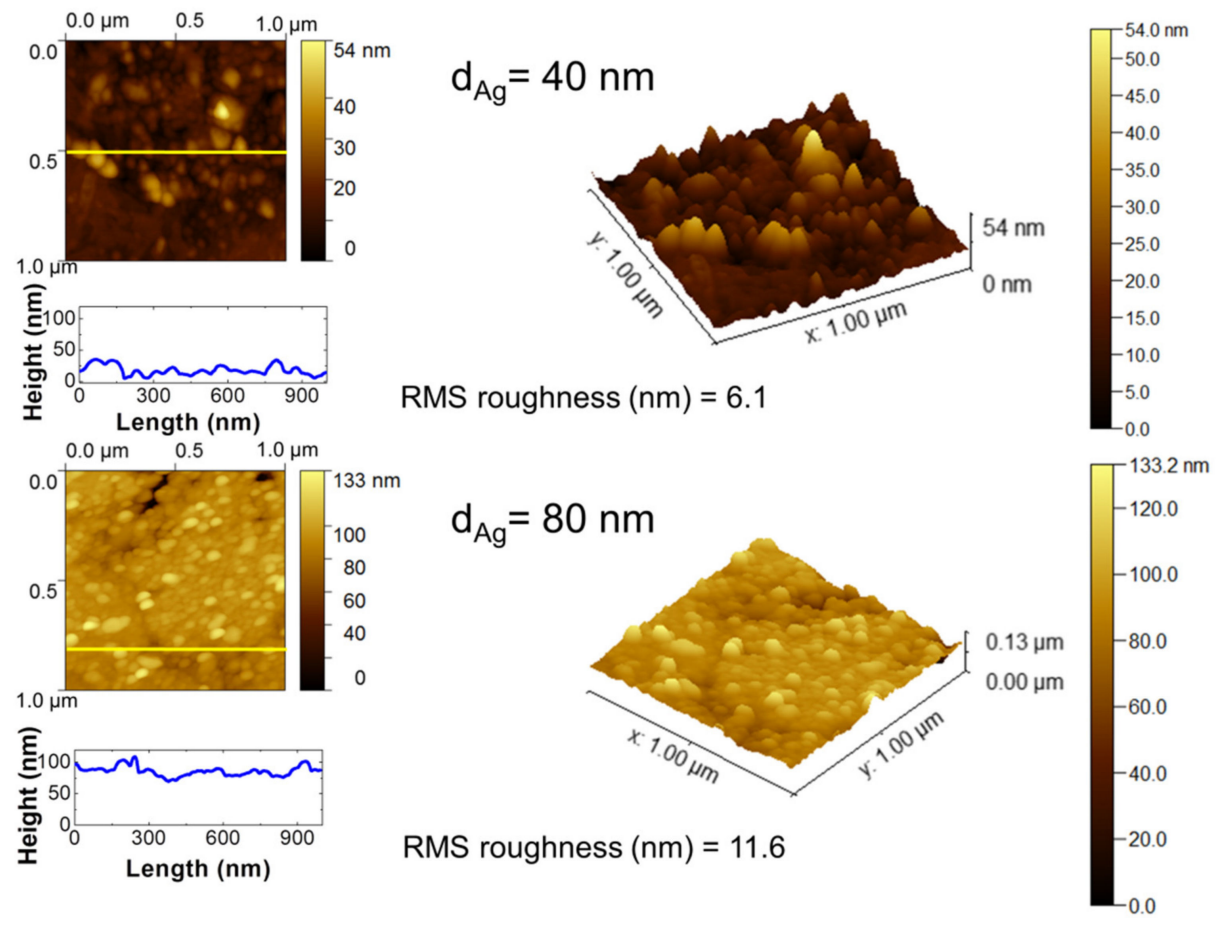

Figure 2. The $2 \mathrm{D}$ and $3 \mathrm{D}$ AFM topography scan images on $1 \mu \mathrm{m} \times 1 \mu \mathrm{m}$ areas of vacuum-thermalevaporated silver layers on glass substrates with nominal thicknesses of $d_{A g}=40 \mathrm{~nm}$ and $d_{A g}=80 \mathrm{~nm}$, as indicated. The RMS roughness values are indicated. Cross-sectional surface line profiles obtained from the yellow lines of the corresponding AFM micrograph images are depicted.

In the low annealing temperature regime, which takes place at temperatures up to $\mathrm{T}_{\mathrm{A}}=250{ }^{\circ} \mathrm{C}$, the formation of irregular and elongated clusters is observed in the $\mathrm{d}_{\mathrm{Ag}}=40 \mathrm{~nm}$ (Figure $3 \mathrm{~b}$ ) samples, and in $\mathrm{d}_{\mathrm{Ag}}=80 \mathrm{~nm}$ samples, the presence of coalesced nanostructures and a high percolation degree is noticeable (Figure $4 \mathrm{~b}$ ). Figure $4 \mathrm{~b}$ also shows the first stages of hole formation. As the $\mathrm{T}_{\mathrm{A}}$ increases from $300{ }^{\circ} \mathrm{C}$ to $450{ }^{\circ} \mathrm{C}$ (in the case of samples with $\mathrm{d}_{\mathrm{Ag}}=40 \mathrm{~nm}$ ) or $500^{\circ} \mathrm{C}$ (in the case of samples with $\mathrm{d}_{\mathrm{Ag}}=80 \mathrm{~nm}$ ), those previously observed structures lead to well-separated islands that agglomerate into elongated and oval nanoparticles, as seen Figures $3 c-$ e and $4 c-e$, and the oval-like nanoparticles will shrink into spherical nanoparticles with a relatively uniform size at elevated temperatures (Figures $3 \mathrm{f}$ and $4 \mathrm{f}$ ) due to surface tension. In particular, in Figure 3b, the colored arrows indicate specific features occurring during the annealing step of the SSD process.

The hole coalescence can be recognized in different situations, i.e., two particles connected by a residual filament alone (indicated by the yellow arrow); two big particles connected by a neck (indicated by the dark orange arrow) and two filaments that are in contact and about to separate (indicated by the light green arrow). Similarly, in Figure 4b, it can be seen two big grains are still attached by an isthmus, which is indicated by a yellow arrow. The further evolution of the dewetting process (in this case by increasing $\mathrm{T}_{\mathrm{A}}$ ) leads to the shrinking of the diameter of the filaments until complete filament rupture occurs and round silver nanoparticles are formed.

The size distribution histograms corresponding to the morphological quantitative study of those silver nanoparticle arrays depicted in Figures 3 and 4 are presented in Figures S1 and S2, respectively. Providing the basis for these results, Figure 5a shows plots of the mean size (D) of the formed Ag NP arrays as a function of the annealing temperature $\mathrm{T}_{\mathrm{A}}$ for silver precursor layer samples with the two different thickness, i.e., $\mathrm{d}_{\mathrm{Ag}}=40 \mathrm{~nm}$ and $80 \mathrm{~nm}$. It can be appreciated that the Ag NPs that were formed from a precursor layer with 
a thickness of $80 \mathrm{~nm}$ exhibited greater mean sizes than those obtained from a silver layer with a thickness of $40 \mathrm{~nm}$, irrespective of the annealing temperature. As mentioned above, one of the critical parameters controlling the final morphology of the silver NPs is thin film thickness, $d_{A g}$. The initial film thickness is the main parameter that determines $D$, whereas the annealing temperature is responsible for obtaining round nanoparticles [62]. The increase in Ag NP size as the precursor for the increases in the film thickness is consistent with what has been stated and documented in the literature [60,62-64]. In fact, in the SSD process, $\mathrm{D}$ is proportional to $\mathrm{d}_{\mathrm{Ag}}$, according to the theoretical basis described elsewhere, and this will be presented and discussed later in this work [47,60]. Moreover, it can be seen that for both precursor layer thicknesses (40 and $80 \mathrm{~nm}$ ), the mean size of the Ag NPs decrease slightly as the annealing temperature increases (see Figure 5a). This behavior is in line with that reported by Serrano et al. for SSD-dewetted silver NPs formed on soda lime glass substrates (from Ag films with similar thicknesses, $30 \mathrm{~nm}$ and $50 \mathrm{~nm}$ ) and by applying a similar annealing temperature range as the one in the present work; however, a different annealing temperature-time profile was used [38]. However, Serrano et al. reported a decrease in the Ag NP size of about $2 \mathrm{~nm}$ per degree Celsius, and in our case, a slight nanoparticle size decrease of about $0.5 \mathrm{~nm}$ per degree Celsius was observed. Oliva-Ramirez et al. also reported that the particle size decreases as the temperature increases during the SSD-induced formation of AuNi alloy nanoparticles [65].

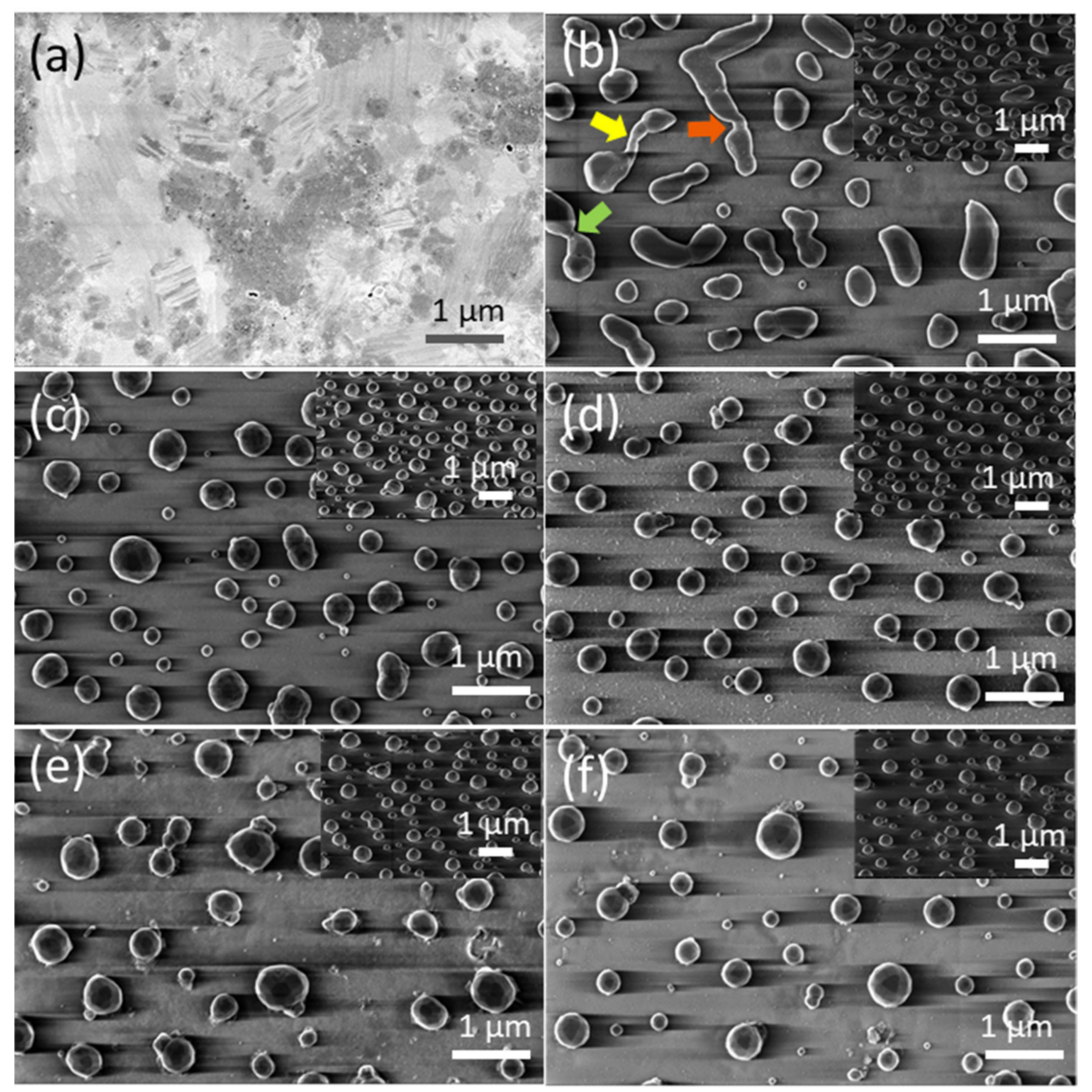

Figure 3. Top views of the FE-SEM micrographs of vacuum-thermal-evaporated silver layers with a nominal thickness $\mathrm{d}_{\mathrm{Ag}}=40 \mathrm{~nm}$ at different stages of the annealing step during the SSD process applying the heat-up region program depicted in Figure 1 and ending at different TA values: (a) as-grown silver layer, (b) $\mathrm{T}_{\mathrm{A}}=250{ }^{\circ} \mathrm{C}$, (c) $\mathrm{T}_{\mathrm{A}}=300{ }^{\circ} \mathrm{C}$, (d) $\mathrm{T}_{\mathrm{A}}=350{ }^{\circ} \mathrm{C},(\mathbf{e}) \mathrm{T}_{\mathrm{A}}=400{ }^{\circ} \mathrm{C}$, and (f) $\mathrm{T}_{\mathrm{A}}=450{ }^{\circ} \mathrm{C}$. The insets depict the corresponding tilted FE-SEM micrograph views (with a tilt angle of $52^{\circ}$ ). The colored arrows in (a) highlight specific features of the dewetting process, leading to the formation of silver nanoparticles. Temperature ramp rate $=10^{\circ} \mathrm{C} / \mathrm{min}$. In all of these cases, a soda lime glass substrate has been used. 


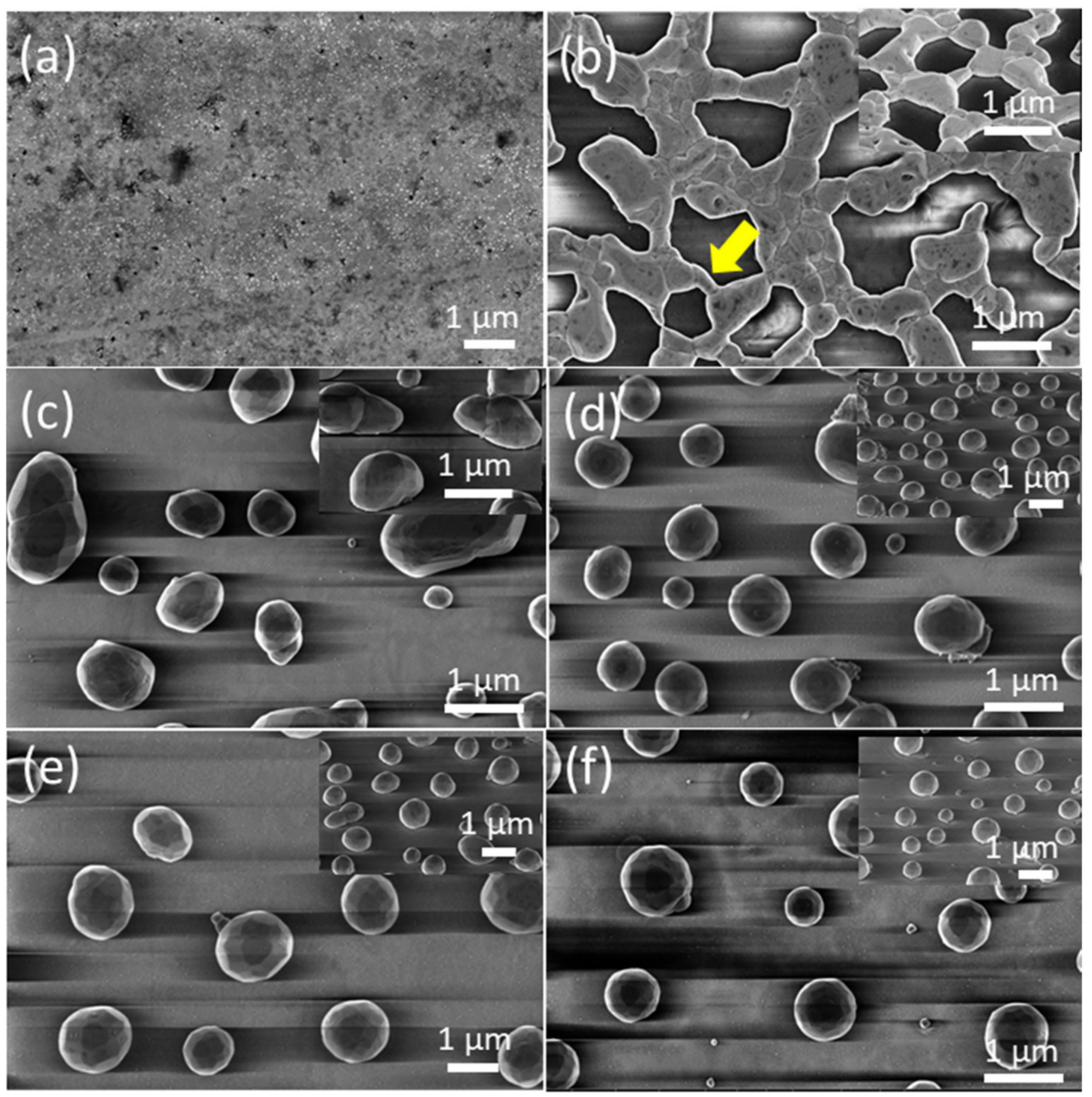

Figure 4. Top views of the FE-SEM micrographs of vacuum-thermal-evaporated silver layers with a nominal thickness $\mathrm{d}_{\mathrm{Ag}}=80 \mathrm{~nm}$ at different stages of the annealing step during the SSD process applying the heat-up region program depicted in Figure 1 and ending at different $\mathrm{T}_{\mathrm{A}}$ values: (a) as-grown silver layer, (b) $\mathrm{T}_{\mathrm{A}}=250{ }^{\circ} \mathrm{C}$, (c) $\mathrm{T}_{\mathrm{A}}=300{ }^{\circ} \mathrm{C}$, (d) $\mathrm{T}_{\mathrm{A}}=350{ }^{\circ} \mathrm{C},(\mathbf{e}) \mathrm{T}_{\mathrm{A}}=400{ }^{\circ} \mathrm{C}$, and $(\mathbf{f}) \mathrm{T}_{\mathrm{A}}=500{ }^{\circ} \mathrm{C}$. The insets depict the corresponding tilted FE-SEM micrograph views (with a tilt angle of $52^{\circ}$ ). The yellow arrow in (b) highlights specific features of the dewetting process, leading to the formation of the silver nanoparticles. Temperature ramp rate $=10^{\circ} \mathrm{C} / \mathrm{min}$. In all cases, a soda lime glass substrate has been used.

Figure $5 \mathrm{~b}$ shows plots of the silver nanoparticle surface density $(\mathrm{N})$ as a function of the annealing temperature $\mathrm{T}_{\mathrm{A}}$ for samples with two different silver precursor layer thickness, i.e., $\mathrm{d}_{\mathrm{Ag}}=40 \mathrm{~nm}$ and $80 \mathrm{~nm}$. It can be seen that the surface density of the Ag NPs formed from a precursor layer with a thickness of of $\mathrm{d}_{\mathrm{Ag}}=40 \mathrm{~nm}$ exhibited greater $\mathrm{N}$ values than those obtained from a silver layer with a thickness of of $\mathrm{d}_{\mathrm{Ag}}=80 \mathrm{~nm}$, irrespective of the annealing temperature. As reported in the literature, variations in the NP density $\mathrm{d}_{\mathrm{Ag}}{ }^{-2}$ are expected [60], and the results presented in Figure 5b are in agreement with these statements. Furthermore, it can be seen that for both precursor layer thicknesses, the surface density of the Ag NPs decrease slightly as the annealing temperature $\mathrm{T}_{\mathrm{A}}$ increases (see Figure 5b). Serrano et el. [38] observed that as the covered area decreases, the island height and catchment area increases when the annealing temperature is higher. This can be associated with a decrease in the density. 

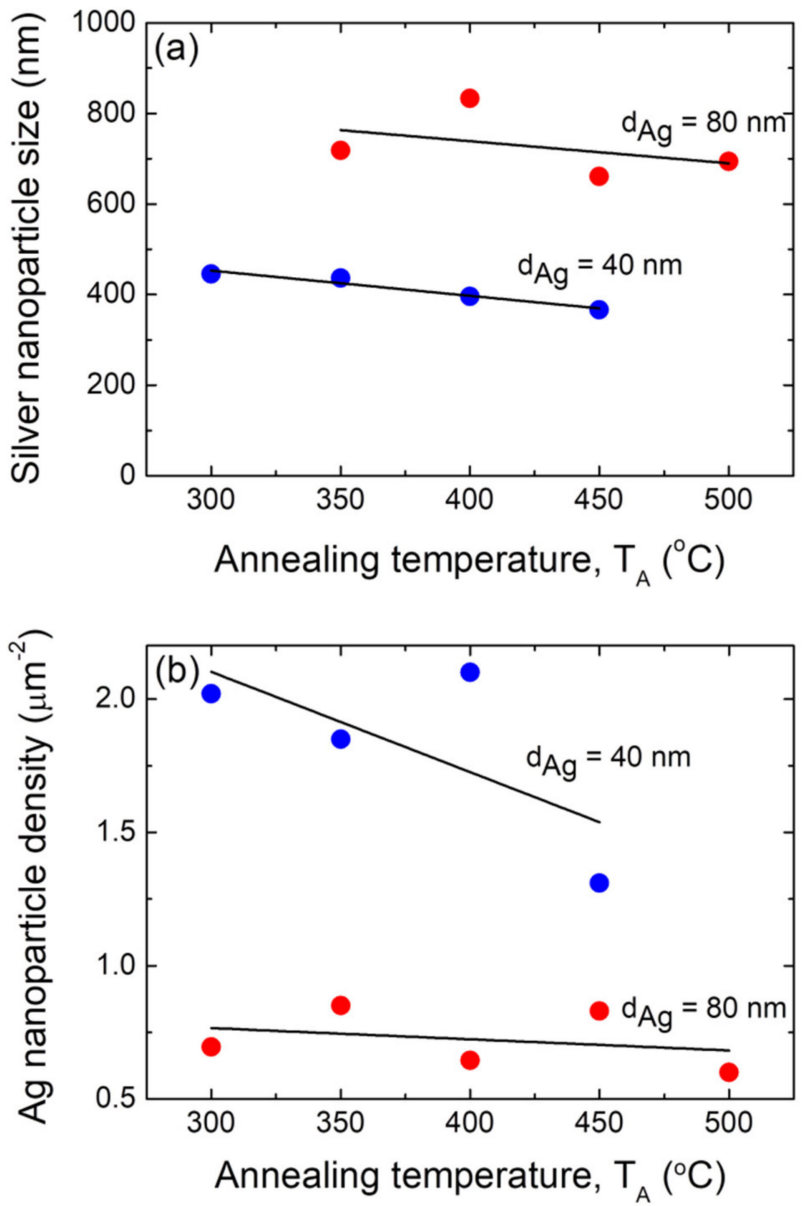

Figure 5. (a) Plot of the average size of the silver nanoparticles as a function of the annealing temperature $\mathrm{T}_{\mathrm{A}}$ of the annealing step during the SSD process. (b) Plot of surface density of the silver nanoparticles as a function of the annealing temperature $\mathrm{T}_{\mathrm{A}}$ during the annealing step of the SSD process. Two different precursor silver layer thickness were studied, i.e., $\mathrm{d}_{\mathrm{Ag}}=40 \mathrm{~nm}$ (blue circles) and $80 \mathrm{~nm}$ (red circles). In all of these samples, the heat-up region program previously depicted has been applied. The black lines are a guide for the eyes.

The organization of the supported metallic nanoparticles is required for nanotechnology applications $[55,66]$. To quantify the ordering, we calculated the experimental radially averaged autocorrelation function $(\mathrm{g}(\mathrm{r}))$ using FE-SEM micrograph images $[36,37,55,65,67]$. The autocorrelation of the pixels in a binary micrograph image as a function of their radial distance (also known as pair correlation) was used to determine the radially averaged autocorrelation. As an example of this procedure, the pair correlation function plot for the silver nanoparticles generated from an $80 \mathrm{~nm}$ thick Ag layer annealed at $\mathrm{T}_{\mathrm{A}}=350{ }^{\circ} \mathrm{C}$ is shown in Figure 6a, which corresponds to an FE-SEM micrograph image from Figure $4 \mathrm{c}$ (see Figures S3 and S4 for plots of the $\mathrm{g}(\mathrm{r})$ functions for the silver nanoparticle array samples formed under the other studied conditions of $\mathrm{d}_{\mathrm{Ag}}$ and $\mathrm{T}_{\mathrm{A}}$ ). The first maximum indicates the characteristic length (particle spacing), $\lambda_{\mathrm{ch}}$. The $\mathrm{g}(\mathrm{r})$ function plot depicted in Figure $6 \mathrm{a}$ exhibits a peak at about $1.1 \mu \mathrm{m}$, which indicates that the silver NPs have a positional correlation, and the characteristic particle spacing $\lambda_{\mathrm{ch}}$ of the positional correlation is about $1.1 \mu \mathrm{m}$. The obtained characteristic particle spacing for each sample is plotted as a function of the annealing temperature, $T_{A}$, for the two different silver layer thicknesses $\left(\mathrm{d}_{\mathrm{Ag}}=40 \mathrm{~nm}\right.$ and $80 \mathrm{~nm}$, as indicated) as an inset of Figure 6a. It can be appreciated that the Ag NPs formed from a precursor layer with a thickness of $80 \mathrm{~nm}$ exhibited greater characteristic particle spacing values than those obtained from a silver layer with a thickness of of $40 \mathrm{~nm}$, irrespective of the annealing temperature. 

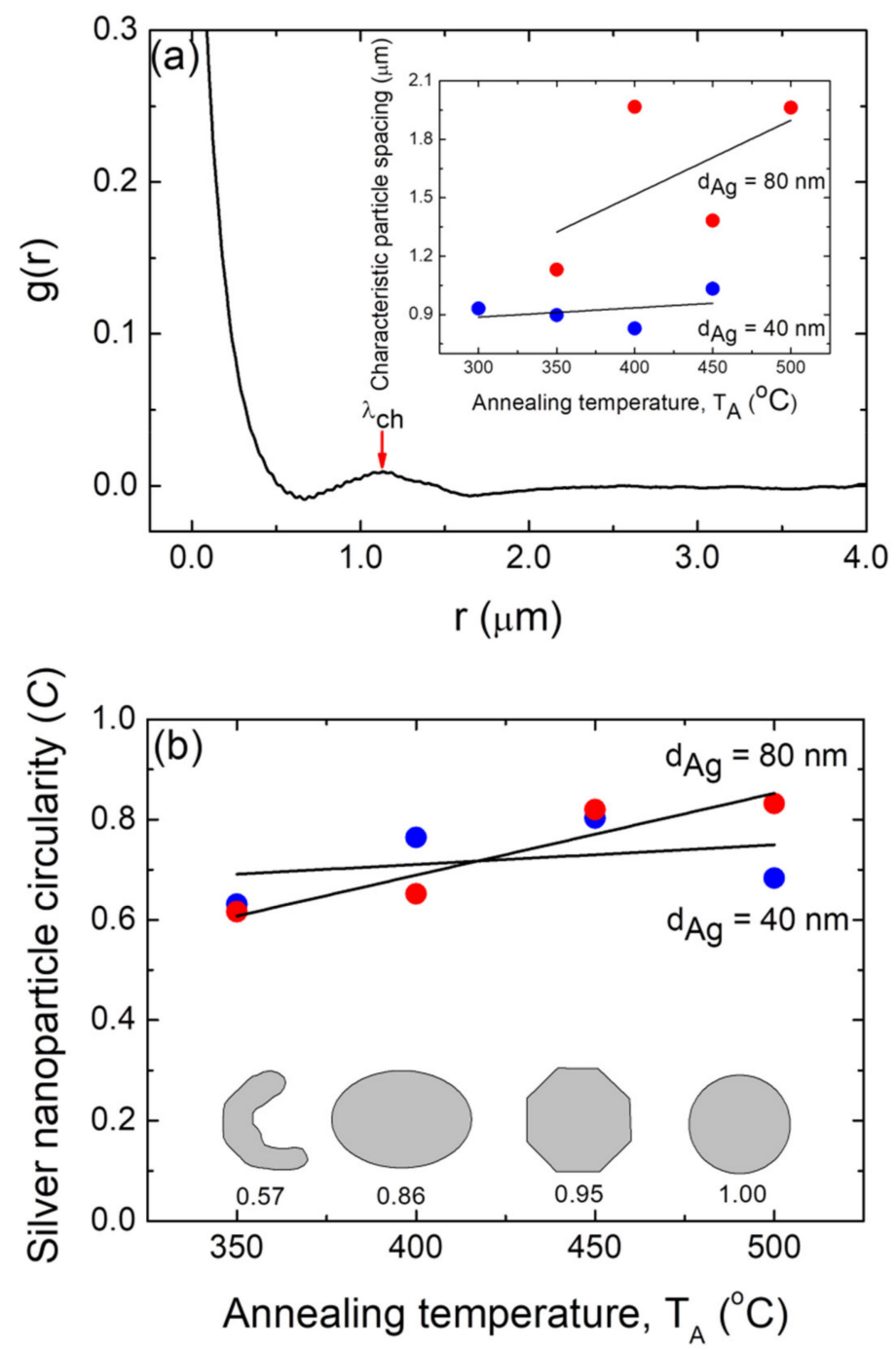

Figure 6. (a) Typical measured radially averaged autocorrelation function, $g(r)$, for the silver nanoparticle positions for a typical sample with $\mathrm{d}_{\mathrm{Ag}}=80 \mathrm{~nm}$ and $\mathrm{T}_{\mathrm{A}}=350{ }^{\circ} \mathrm{C}$. Arrow indicates the corresponding characteristic particle spacing $\lambda_{\mathrm{ch}}$ (at maximum). Inset: positional correlation as a function of the annealing temperature, $T_{A}$, for samples with two different thicknesses: $d_{A g}=40 \mathrm{~nm}$ (blue circles) and $80 \mathrm{~nm}$ (red circles). (b) Mean circularity of the silver nanoparticles formed as a function of the annealing temperature, TA, for samples with two different thicknesses: $\mathrm{d}_{\mathrm{Ag}}=40 \mathrm{~nm}$ (blue circles) and $80 \mathrm{~nm}$ (red circles). Inset: elongated, oval, polyhedral, and circular shapes and their corresponding circularities. In all of these figures, the black lines are guides for the eyes.

The increase in the $\lambda_{\mathrm{ch}}$ values as the precursor for the increases in the thin film thickness is consistent with what has been said and documented in the literature for gold nanoparticles formed through the SSD process [55]. Moreover, as depicted in the inset of Figure $6 \mathrm{a}$, the Ag NP arrays formed from a precursor layer with a thickness of $40 \mathrm{~nm}$ exhibited almost constant $\lambda_{\mathrm{ch}}$ values as a function of $\mathrm{T}_{\mathrm{A}}$. On the other hand, those Ag NP array samples that were obtained from a precursor layer with $\mathrm{d}_{\mathrm{Ag}}=80 \mathrm{~nm}$ exhibited an increase in the $\lambda_{\mathrm{ch}}$ values as a function of $\mathrm{T}_{\mathrm{A}}$ (see inset of Figure $6 \mathrm{a}$ ), which is in agreement with previously reported results [36]. In fact, as discussed above, as the annealing temperature increases, smaller and less surface dense Ag NPs are obtained, resulting in the averaged inter-particle distance increasing, which can be seen in the inset of Figure 6a.

To further quantify those observations about the shape of the Ag NPs, Figure $6 \mathrm{~b}$ presents their mean circularity $C$ as a function of the annealing temperature $T_{A}$ for samples 
with silver precursor layers with the two thicknesses used in this study, i.e., $\mathrm{d}_{\mathrm{Ag}}=40 \mathrm{~nm}$ and $80 \mathrm{~nm}$. This parameter $C$ is a shape descriptor (in-plane projected shape) that compares the actual area of the nanoparticles to that of a virtual circle of the radius $r$ determined by the perimeter $P(r=P / 2 \pi)$ [65]. Highly circular silver nanoparticles have the desired shape condition for the excitation of the narrower full-width half maxima of the localized surface plasmon resonance surface enhanced by spectroscopy as well as for sensors [68]. As can be appreciated in Figure 6b, by definition, a perfectly circular particle has a circularity of 1, whereas elongated, oval, or faceted particles have a circularity of less than one [65]. Figure $6 \mathrm{~b}$ illustrates that at lower temperatures, Ag NPs are more elongated, and as the temperature rises, they become rounder. However, for the $\mathrm{d}_{\mathrm{Ag}}=40 \mathrm{~nm}$ case, lower $C$ values and a less pronounced effect with $T_{A}$ compared to those of the $d_{A g}=80 \mathrm{~nm}$ samples can be appreciated.

To examine the kinetic evolution of the precursor silver layers in greater depth, i.e., to study the effect of the annealing time $t_{\mathrm{A}}$ on the morphological properties of the formed silver nanoparticles, the constant temperature region (temperature-time plateau) depicted in Figure 1 was applied to the precursor silver layers. Figure 7 shows FE-SEM micrograph images of vacuum-thermal-evaporated silver layers with a nominal thickness $d_{A g}=80 \mathrm{~nm}$ at different stages of the annealing step during the SSD process (by applying the temperaturetime plateau region program depicted in Figure 1), with $\mathrm{T}_{\mathrm{A}}=500{ }^{\circ} \mathrm{C}$ and ending at different $t_{A}$ values, as indicated (see Figure S5 for a similar study with $d_{A g}=40 \mathrm{~nm}$ and $T_{A}=450{ }^{\circ} \mathrm{C}$ ). It can be appreciated that for $\mathrm{t}_{\mathrm{A}}=8 \mathrm{~min}$ (see Figure 7a) and despite the short annealing time, only well-separated hemispherical silver nanoparticles can be seen (without the presence of percolated nanostructures), which is in agreement to particles depicted in Figure $4 \mathrm{f}$, indicating the main role of $\mathrm{T}_{\mathrm{A}}$ over $\mathrm{t}_{\mathrm{A}}$.

Moreover, as the annealing time increased, the mean size of the hemispherical silver nanoparticles increase D. The size distribution histograms corresponding to the morphological quantitative study of those silver nanoparticle arrays depicted in Figure 7 are presented in Figure S6. As the basis of these results, Figure 8a shows plots of the mean size (D) and surface density $(\mathrm{N})$ of the formed Ag NP arrays as a function of the annealing time $t_{\mathrm{A}}$ at the annealing temperature of $500{ }^{\circ} \mathrm{C}$. It can be seen that as the annealing time increases, the mean size of the silver nanoparticles increases, whereas their surface density decreases.

The overall evolution of silver nanoparticle morphology, size, and density can be discussed based on the interplay between temperature-induced surface diffusion, the sublimation of silver atoms as well the surface energy minimization mechanism [49]. In fact, after the formation of the Ag NPs through the SSD mechanism, the concurrent impacts of surface diffusion, Ostwald's ripening, and Ag sublimination can be used to explain the evolution of the morphology of these silver nanoparticles, which will be further addressed $[6,10,30]$. The temperature-dependent surface diffusion coefficient $\left(D_{S}\right)$ can be expressed by the following relationship [6,10]:

$$
D_{S} \propto e^{-\frac{E_{A g}}{k T}}
$$

where $T_{A}$ is the annealing temperature, $K$ is the Boltzmann's constant, and $E_{A g}$ is the activation energy for diffusion of $\mathrm{Ag}$ ad-atoms. It is obvious that at a higher annealing temperature $T_{A}$, the diffusion length (i.e., ad-atom displacement) can be larger, but at a lower temperature, it may be limited. On the other hand, high activation energy values lead to lower ad-atoms diffusion lengths. 

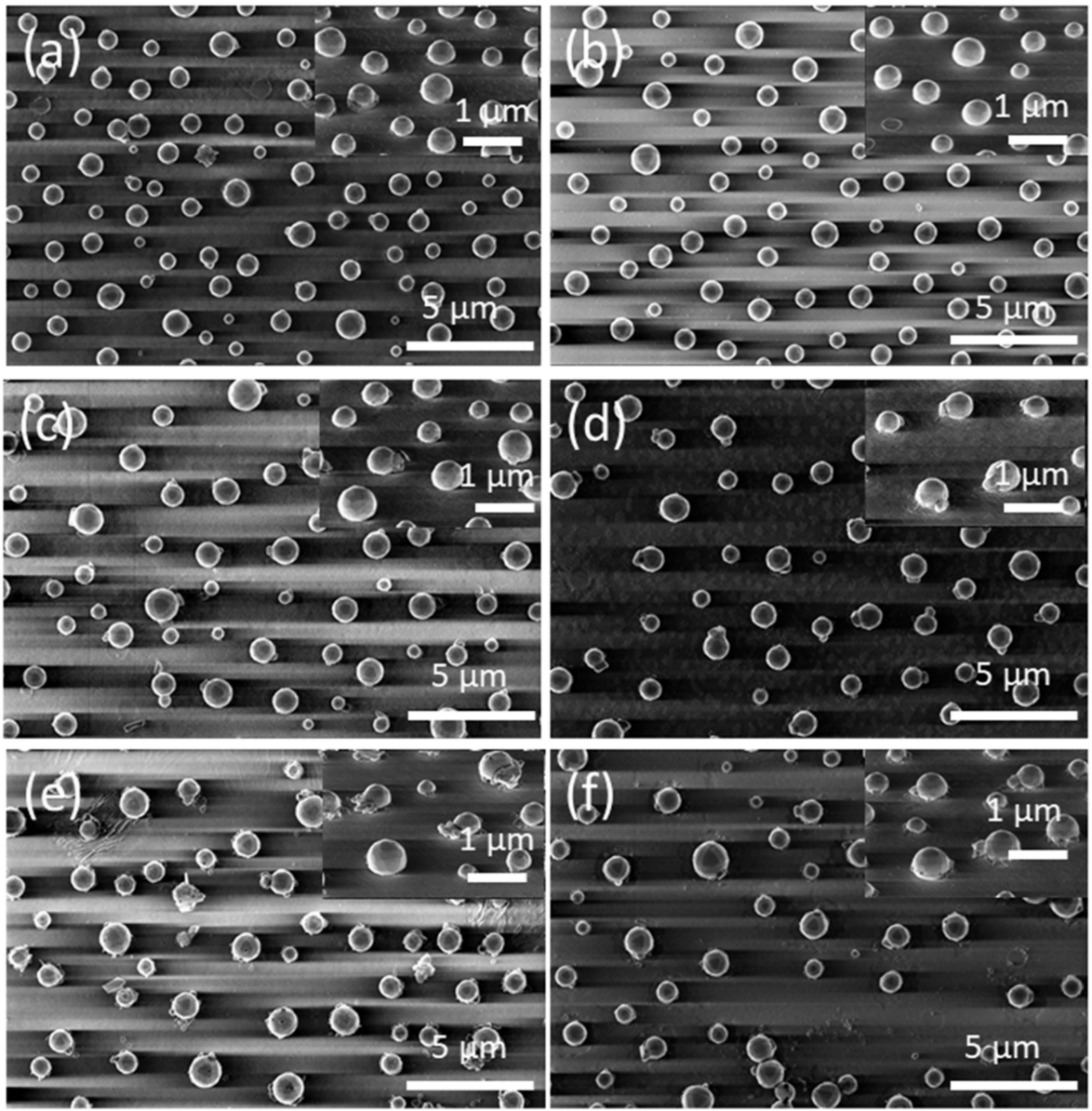

Figure 7. Top views of FE-SEM micrographs of vacuum-thermal-evaporated silver layers with a nominal thickness $\mathrm{d}_{\mathrm{Ag}}=80 \mathrm{~nm}$ at different stages of the annealing step during the SSD process applying the constant temperature region program depicted in Figure 1 at $\mathrm{T}_{\mathrm{A}}=500{ }^{\circ} \mathrm{C}$ and ending at different $t_{A}$ values: (a) $t_{A}=8 \mathrm{~min},(b) t_{A}=17 \min ,(c) t_{A}=26 \min ,(d) t_{A}=34 \mathrm{~min},(e) t_{A}=42 \mathrm{~min}$, and $(\mathbf{f}) \mathrm{t}_{\mathrm{A}}=51 \mathrm{~min}$. The insets depict the corresponding tilted FE-SEM micrograph views (with a tilt angle of $52^{\circ}$ ). Temperature ramp rate $=10^{\circ} \mathrm{C} / \mathrm{min}$. In all of these, cases a soda lime glass substrate has been used.

Simultaneously, the metallic nanostructure evolution associated with the longer annealing duration at a fixed diffusion length with a constant annealing temperature can be described by the Ostwald's ripening $[6,10,30]$. In the case of Ostwald's ripening, as larger particles are more energetically stable than smaller ones, a driven spontaneous process occurs in which the larger NPs grow in size at the expense of the smaller ones as the annealing duration increases, as shown by the scheme in the inset of Figure $8 b[6,10,30,69]$. The difference in the chemical potential of atoms in nanoparticles of various sizes is the main driving factor for ripening [3]. Generally, the size of metallic NPs increases with the longer annealing duration based on Ostwald's ripening, as previously discussed $[6,10,30,69]$.

As described above, one of the dominant kinetic pathways for nanoparticle coarsening during the SSD process is Ostwald ripening (OR). OR kinetics can be divided into two extreme regimes: (a) terrace-diffusion-limited transport (with no significant barrier for attachment of diffusing species to cluster edges) and (b) attachment-detachment-limited transport (with a large attachment barrier) [30,70]. The last regime demonstrates mean field behavior, in which the average cluster size determines whether the cluster grows or decays $[30,70]$, and in this regime case, the average nanoparticle radius $R_{a v}$ scales with time $(t)$ as follows [70]:

$$
R_{a v} \propto t^{\frac{1}{2}}
$$



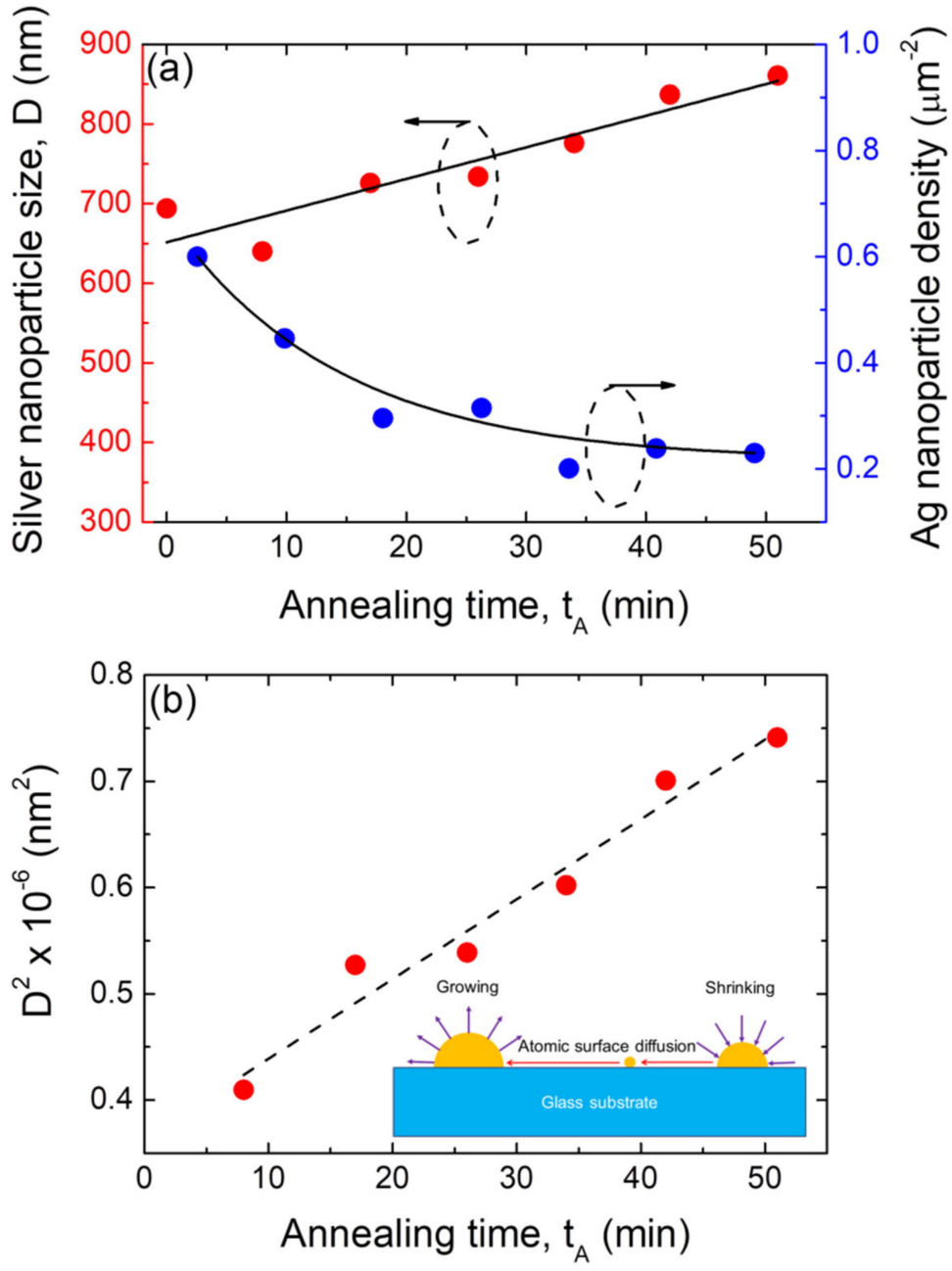

Figure 8. (a) Plots of the average size of the nanoparticles (D) and silver nanoparticle surface density as a function of the annealing time $t_{A}$ of the annealing step of the SSD process. (b) Plot of the average size silver nanoparticles (D), where the square is a function of the annealing time $t_{A}$ of the annealing step during the SSD process. The dashed black line corresponds to the linear fitting. SSD process for silver vacuum-thermal-evaporated layers with a nominal thickness of $d_{A g}=80 \mathrm{~nm}$ applying the constant temperature region program depicted in Figure 1 at $\mathrm{T}_{\mathrm{A}}=500{ }^{\circ} \mathrm{C}$. The solid black lines are guides for the eyes. Inset: Schematic to illustrate the diffusion of Ag ad-atoms and Ostwald's Ag ripening during annealing.

As such, by plotting the square of the formed silver nanoparticle size vs. time, linear behavior is expected. In fact, Figure $8 \mathrm{~b}$ shows a plot of the square of the experimental data for the silver nanoparticle size $\mathrm{D}^{2}$ as a function of the annealing time $t_{\mathrm{A}}$, which displays a linear relationship with good linear fitting $(r=0.982)$. This confirms the validity of Ostwald ripening under the conditions of attachment-detachment-limited transport regime for the growth of Ag NPs on glass substrates by means of the SSD process. Similar behavior was observed for the silver NPs that were formed from a precursor layer with a thickness of $40 \mathrm{~nm}$ and annealed at $\mathrm{T}_{\mathrm{A}}=450{ }^{\circ} \mathrm{C}$ at different times (see Figure S7). On the other hand, Figure 8a shows that as a consequence of the size growth of the Ag NPs as the annealing time increases, the Ag NP surface density decreases (based on mass conservation, bigger NPs have been formed but with lower quantity of them per unit area). The latter is also explained in Figure 9a, i.e., the increase in characteristic particle spacing with increased the annealing times. 

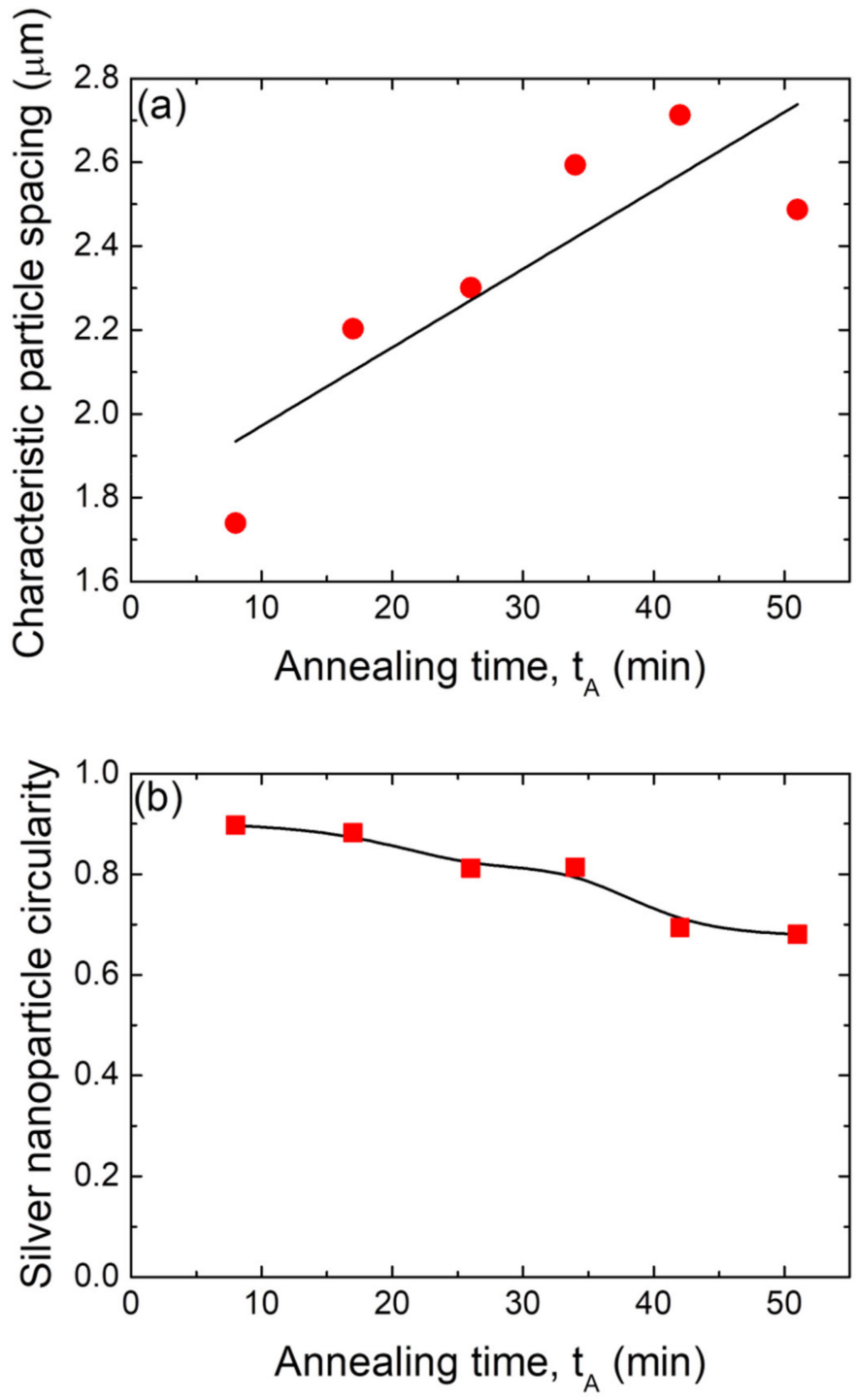

Figure 9. (a) Positional correlation as a function of the annealing time, $t_{A}$, for samples with $\mathrm{d}_{\mathrm{Ag}}=80 \mathrm{~nm}$ and annealed at $\mathrm{T}_{\mathrm{A}}=500^{\circ} \mathrm{C}$. (b) Mean circularity of the silver nanoparticles formed as a function of the annealing time, $t_{A}$, for samples with $\mathrm{d}_{\mathrm{Ag}}=80 \mathrm{~nm}$ and annealed $\mathrm{T}_{\mathrm{A}}=500{ }^{\circ} \mathrm{C}$. In all of these figures, the black lines are guides for the eyes.

Figure $9 \mathrm{~b}$ presents the mean circularity $C$ of silver nanoparticles (obtained from a precursor silver layer with $\mathrm{d}_{\mathrm{Ag}}=80 \mathrm{~nm}$ and annealed at $\mathrm{T}_{\mathrm{A}}=500{ }^{\circ} \mathrm{C}$ ), as a function of the SSD annealing time. The Ag NP circularity with $C=0.9$ remains nearly constant up to $20 \mathrm{~min}$, but for greater times, it slowly decreases in steps to 0.7 at $\mathrm{t}_{\mathrm{A}}=51 \mathrm{~min}$. As seen above (see Figure 8a), at longer times, larger Ag NPs are attained, indicating that this growth stage is also witness to a slight decrease in circularity, which means that at different stages of growth, larger particles have more asymmetry in their shape [68].

A study of the effect of the initial precursor silver layer thickness on the final formed Ag NP morphology was conducted. As example, FE-SEM micrograph images of vacuumthermal-evaporated silver layers with four nominal thickness values: $d_{\mathrm{Ag}}=20 \mathrm{~nm}, 40 \mathrm{~nm}$, $60 \mathrm{~nm}$, and $80 \mathrm{~nm}$, and annealed at $\mathrm{T}_{\mathrm{A}}=400^{\circ} \mathrm{C}$ (by applying the temperature-time plateau region program depicted in Figure 1) with $\mathrm{t}_{\mathrm{A}}=1 \mathrm{~h}$, as indicated, are depicted in Figure S8. Figure 10a shows an increase in the mean size of the formed Ag NPs as a function of the thickness of the initial silver layer for samples annealed at three different temperatures: $\mathrm{T}_{\mathrm{A}}=350{ }^{\circ} \mathrm{C}, 400{ }^{\circ} \mathrm{C}$, and $450{ }^{\circ} \mathrm{C}$, as indicated, for $\mathrm{t}_{\mathrm{A}}=1 \mathrm{~h}$. 

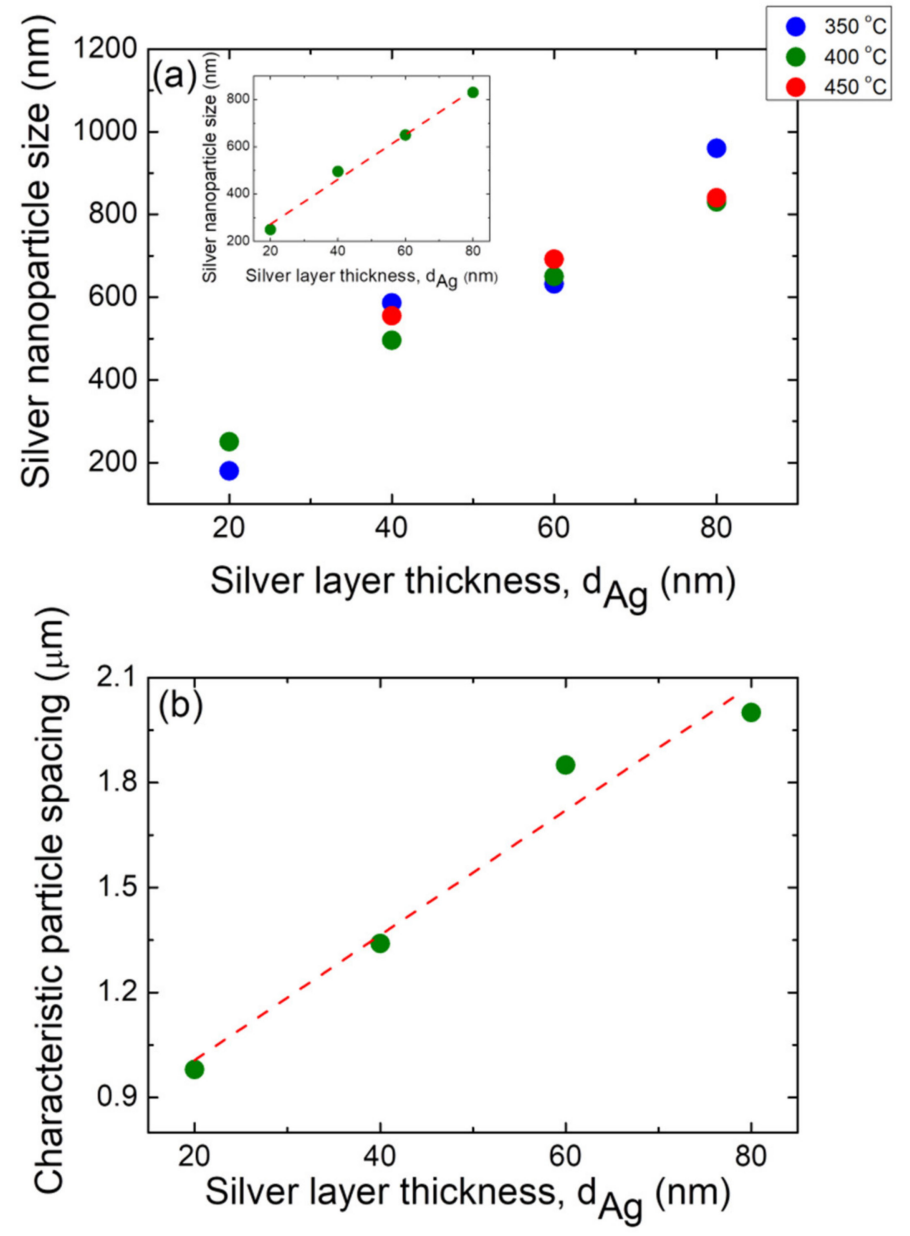

Figure 10. (a) Plot average size of the silver nanoparticles (D) as a function of the initial silver layer thickness, $\mathrm{d}_{\mathrm{Ag}}$, for three different annealing temperatures: $\mathrm{T}_{\mathrm{A}}=350{ }^{\circ} \mathrm{C}$ (blue circles), $\mathrm{T}_{\mathrm{A}}=400{ }^{\circ} \mathrm{C}$ (olive green circles), and $\mathrm{T}_{\mathrm{A}}=450^{\circ} \mathrm{C}$ (red circles). In all cases, an annealing time of $\mathrm{t}_{\mathrm{A}}=1 \mathrm{~h}$ has been applied. Inset: plot detail for the case of the $\mathrm{T}_{\mathrm{A}}=400{ }^{\circ} \mathrm{C}$ case. The dashed red line corresponds to the linear fitting. (b) Positional correlation as a function of the initial silver layer thickness, $\mathrm{d}_{\mathrm{Ag}}$, for samples annealed at $\mathrm{T}_{\mathrm{A}}=400{ }^{\circ} \mathrm{C}$ for $1 \mathrm{~h}$. The dashed red line corresponds to the linear fitting.

In fact, Jiran et al. [71] showed that the void growth rate $R_{v}$ decreases as the film thickness $d$ dramatically increases, i.e., $R_{v} \propto d^{-3}$; tit is then reasonable that both the nanoparticle size and the characteristic particle spacing (vide infra) increases with the precursor film thickness [37]. A linear increase in the mean Ag NP size with the precursor film thickness is also observed, regardless of the annealing temperature. In order to prove this linear behavior, an example is provided in the inset of Figure 10a, which shows a similar $D$ vs. $\mathrm{d}_{\mathrm{Ag}}$ plot, but only for the $\mathrm{T}_{\mathrm{A}}=400{ }^{\circ} \mathrm{C}$, and also shows a linear fitting while exhibiting a good Pearson correlation coefficient $(r=0.995)$. This is in agreement with the findings reported in the literature for different layer materials and substrates [28,60,72]. Indeed, a similar linear dependence behavior for dewetted silver and gold films was observed by Morawiec et al. [62] and Kojima et al. [55], respectively. This shows that the initial film thickness is the most important factor in determining the mean NP size, whereas the annealing temperature determines the nanoparticle sphericity [62]. Figure 10b shows a linear increase in the characteristic particle spacing with the increase in the silver precursor film for a typical sample $\left(\mathrm{T}_{\mathrm{A}}=400^{\circ} \mathrm{C}\right.$ and $\left.\mathrm{t}_{\mathrm{A}}=1 \mathrm{~h}\right)$.

In this regard, Wang et al. [37], reported a non-linear behavior of $\lambda_{c h}$ vs. the precursor film thickness in the preparation of gold nanoparticles during SSD process, whereas Kojima et al. [55] reported that Au NPS created with SSD a showed a linear behavior of $\lambda_{\mathrm{ch}}$ vs. the initial precursor film thickness, which was also observed in the present study. 


\subsection{Structural Characterization of the Ag Nanoparticle Arrays}

Figure 11 shows typical $\mathrm{X}$-ray diffraction patterns of as-grown vacuum-thermalevaporated silver layers with a nominal thickness $d_{A g}=80 \mathrm{~nm}$ at different stages of the annealing step during the SSD process (applying the heat-up region program depicted in Figure 1) and ending at selected different $T_{A}$ values, as indicated. At first glance, all the diffraction peaks can be indexed to the cubic silver structure (JCPDS file No. 04-0783) [73]. Four diffraction peaks corresponding to the (111), (200), (311), and (222) crystallographic planes of the cubic silver structure can be clearly identified in the as-grown and the solidstate dewetted samples, except for the sample annealed at $\mathrm{T}_{\mathrm{A}}=500^{\circ} \mathrm{C}$, which only exhibits the peaks at (111), (200), (222).

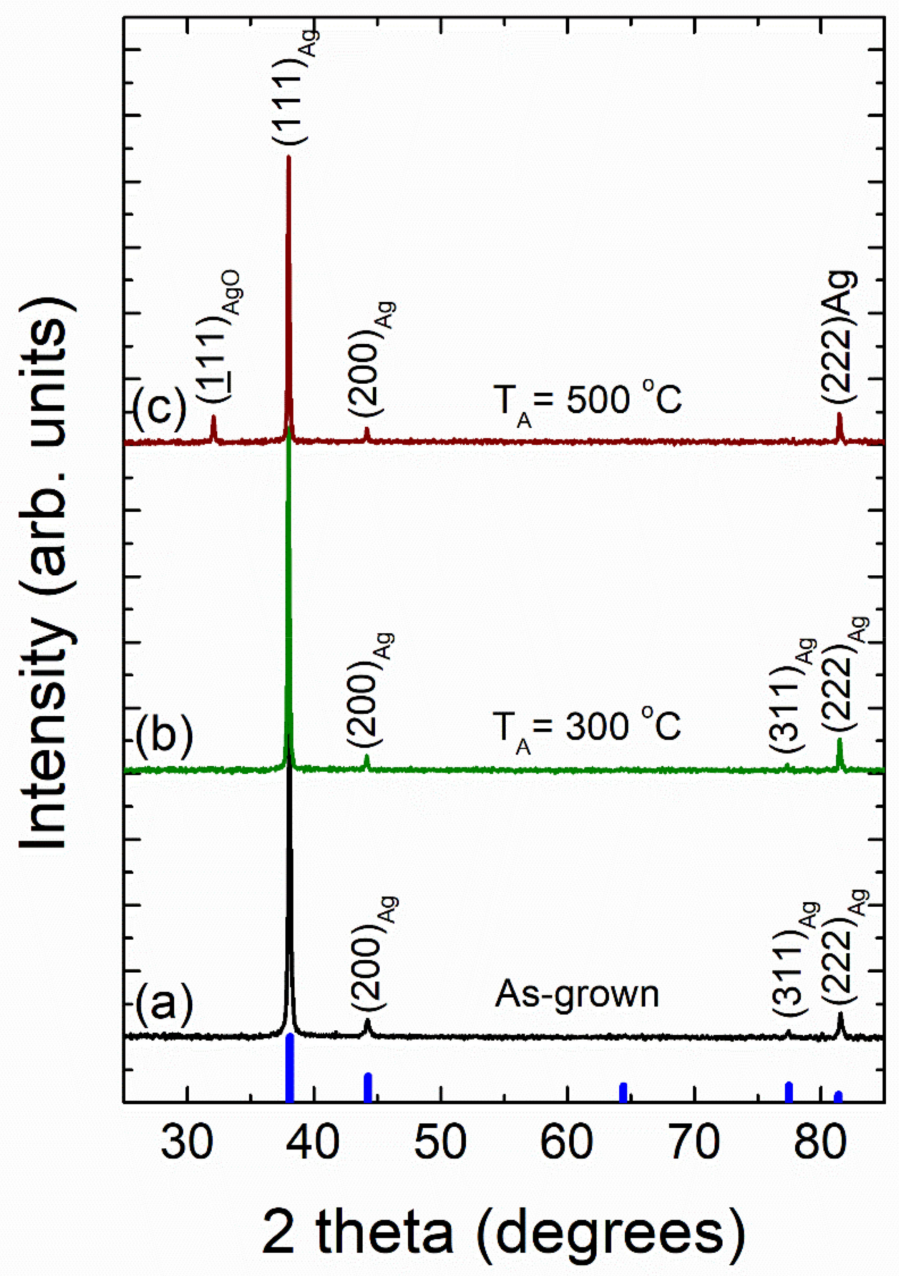

Figure 11. X-ray diffraction patterns of vacuum-thermal-evaporated silver layers with a nominal thickness $\mathrm{d}_{\mathrm{Ag}}=80 \mathrm{~nm}$ at different stages of the annealing step during the SSD process by applying the heat-up region program depicted in Figure 1 and ending at different $\mathrm{T}_{\mathrm{A}}$ values: (a) as-grown silver layer, $(\mathbf{b}) \mathrm{T}_{\mathrm{A}}=300{ }^{\circ} \mathrm{C}$, and $(\mathbf{c}) \mathrm{T}_{\mathrm{A}}=500^{\circ} \mathrm{C}$. Miller indices $(h k l)$ for cubic silver diffraction planes are indicated. Cubic Ag JCPDS pattern is also shown for comparison (thick blue bars). Temperature ramp rate $=10^{\circ} \mathrm{C} / \mathrm{min}$. In all of these cases, a soda lime glass substrate has been used.

Figure 12 shows typical X-ray diffraction patterns of as-grown and vacuum-thermalevaporated silver layers with a nominal thickness $\mathrm{d}_{\mathrm{Ag}}=80 \mathrm{~nm}$ at different stages of the annealing step during the SSD process (applying the temperature-time plateau region program depicted in Figure 1) with $\mathrm{T}_{\mathrm{A}}=500{ }^{\circ} \mathrm{C}$ and ending at different $\mathrm{t}_{\mathrm{A}}$ values, as indicated. 


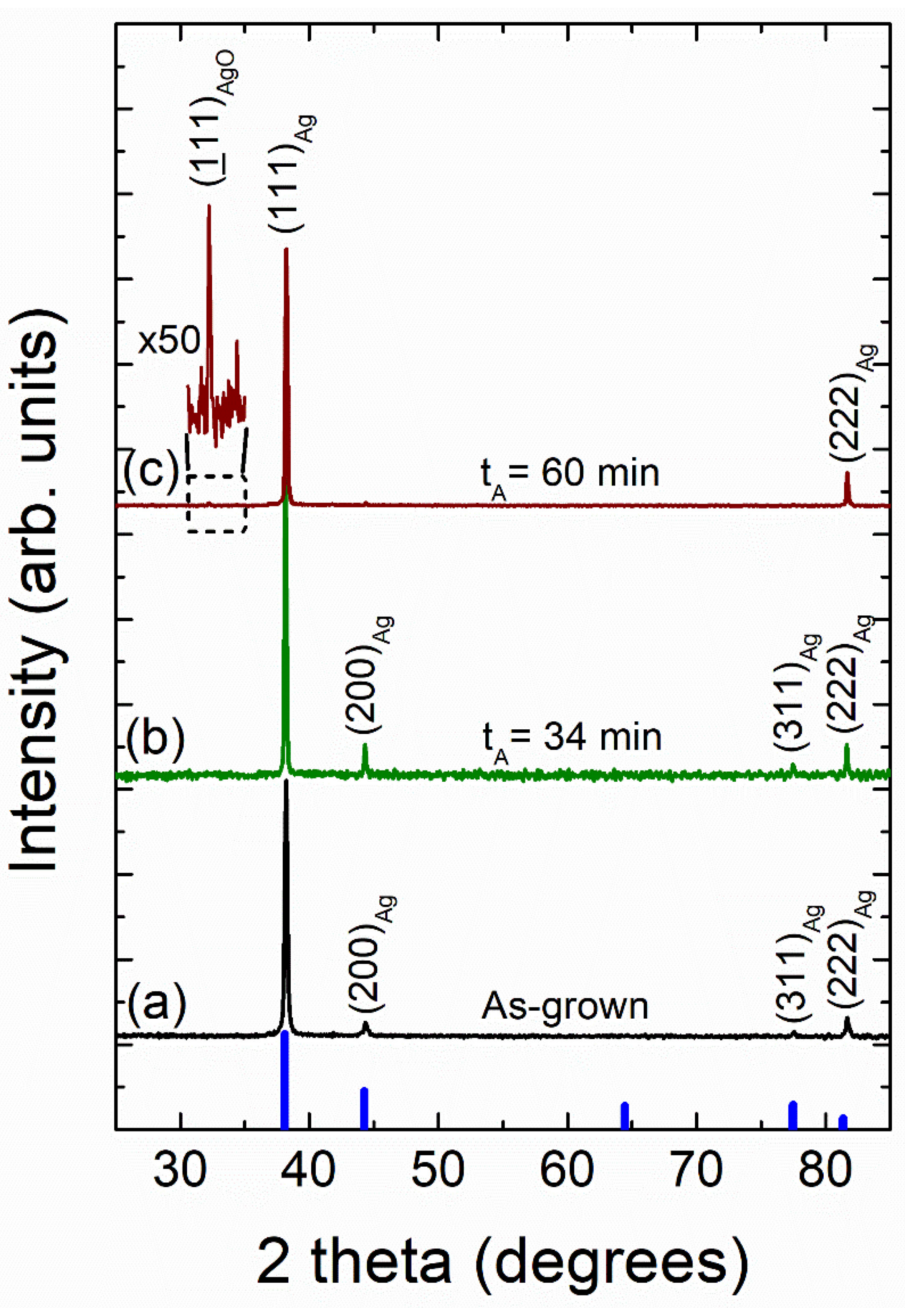

Figure 12. X-ray diffraction patterns of vacuum-thermal-evaporated silver layers with a nominal thickness $\mathrm{d}_{\mathrm{Ag}}=80 \mathrm{~nm}$ at different stages of the annealing step of the SSD process by applying the constant temperature region program depicted in Figure 1 at $\mathrm{T}_{\mathrm{A}}=500{ }^{\circ} \mathrm{C}$ and ending at different $\mathrm{t}_{\mathrm{A}}$ values: (a) as-grown silver layer, $(\mathbf{b}) \mathrm{t}_{\mathrm{A}}=34 \mathrm{~min}$, and (c) $\mathrm{t}_{\mathrm{A}}=60 \mathrm{~min}$. Miller indices $(h k l)$ for cubic silver diffraction planes are indicated. Cubic Ag JCPDS pattern is also shown for comparison (thick blue bars). The zoom of the pattern (c) in the 2 theta region from 30 to 35 degrees depicts a diffraction peak corresponding to the AgO phase. Temperature ramp rate $=10{ }^{\circ} \mathrm{C} / \mathrm{min}$. In all of these cases, a soda lime glass substrate has been used.

Four diffraction peaks corresponding to the (111), (200), (311), and (222) crystallographic planes of the cubic silver structure can be clearly identified in the as-grown and the solid-state dewetted samples, except for the sample annealed during $60 \mathrm{~min}$, which only exhibits the peaks at (111) and (222). In all of the studied cases, the large (111) Ag diffraction peak height (larger than the one expected for a random polycrystalline sample) indicates a strong crystallographic orientation ((111) out-of-plane texture and random in-plane grain orientations). Moreover, the other silver diffraction peaks all present a very low intensity. As a result, both the as-grown film and the silver nanoparticle array samples appear to have significant texturing. In order to quantify this fact, the texture coefficient TC $(h k l)$ was calculated (see SI) [74-77]. The results of the texture analysis of the as-grown silver layers provides a value of $\mathrm{TC}(111)=2.78$ for a maximum of 3.0, indicating that the silver crystallites have a strongly preferred orientation along the $<111>$ crystallographic direction. In general, for non-epitaxial thin film deposition on a substrate, the film surface tends to be crystallographically orientated at either (111) or (001) due to the minimum surface free energy exhibited by these planes [78]. Silver layer samples (with a nominal thickness 
$\mathrm{d}_{\mathrm{Ag}}=80 \mathrm{~nm}$ ), which were submitted to the SSD process at different temperatures $\mathrm{T}_{\mathrm{A}}$ (see XRD patterns in Figure 11), exhibited TC(111) values of approximately 2.8, which are nearly constant independent of the annealing temperature. On the other hand, the texture results on similar silver layer samples submitted at different stages of the annealing step of the SSD process (by applying a $\mathrm{T}_{\mathrm{A}}=500{ }^{\circ} \mathrm{C}$ and ending at different $\mathrm{t}_{\mathrm{A}}$ values, see XRD patterns in Figure 12) showed a very slight increase in the TC(111) value as the $t_{A}$ increased, reaching a $\mathrm{TC}(111)=3.0$ at $\mathrm{t}_{\mathrm{A}}=60 \mathrm{~min}$. As such, as the preferred crystallographic orientation of the studied samples do not show a significant change after the SSD process; it can be inferred that the texturing and of the Ag NPs seems to be determined by the starting silver precursor layer. In fact, as previously observed, dewetted nanoparticle crystallographic alignments are linked to the formation of low-energy facets along specific crystallographic directions, which are substantially influenced by the initial film orientation [28]. In addition, as can be seen in Figures 11 and 12, the silver (111) diffraction peak presents a very sharp profile, indicating that both the as-grown silver layer and the Ag nanoparticles are highly crystalline (high crystallite size values) and have a cubic structure. Crystallite size generally corresponds to the coherent volume in the material for the respective diffraction peak $[79,80]$. An estimation of the size of the crystallite coherent scattering domain $\left(\mathrm{D}_{\mathrm{C}}\right)$ was derived from the Scherrer equation (see SI) and for all cases calculated from the (111) diffraction peak. The as-grown silver films exhibited a $D_{C}=50 \mathrm{~nm}$. Moreover, pristine silver layers submitted to the SSD process either by applying the heat-up region (at different temperatures $\mathrm{T}_{\mathrm{A}}$ ) see $\mathrm{XRD}$ patterns in Figure 11) or by applying the constant temperature region $\left(\mathrm{T}_{\mathrm{A}}=500{ }^{\circ} \mathrm{C}\right.$ and ending at different $t_{A}$ values), see XRD patterns in Figure 12) exhibited $\mathrm{D}_{\mathrm{C}}$ values higher than those of the as-grown ones. The last indication that the SSD process not only triggers the formation of separate silver nanoparticles, but it does so in a concomitant way that increases the sizes of the crystallites. It has been observed that the $\mathrm{D}_{\mathrm{C}}$ increases from 70 to $90 \mathrm{~nm}$ as the $\mathrm{T}_{\mathrm{A}}$ increases from 300 to $500{ }^{\circ} \mathrm{C}$, and it remains nearly constant at $D_{C}=90 \mathrm{~nm}$ with $t_{A}\left(0\right.$ to $80 \mathrm{~min}$, $\left.@ \mathrm{~T}_{\mathrm{A}}=450{ }^{\circ} \mathrm{C}\right)$, showing that the annealing temperature has a greater effect on the crystallite size than the annealing time.

Furthermore, the XRD patterns of the samples annealed at $\mathrm{T}_{\mathrm{A}}=500{ }^{\circ} \mathrm{C}$ and at $\mathrm{T}_{\mathrm{A}}=500^{\circ} \mathrm{C}$ for $60 \mathrm{~min}$ (by applying in each case the heat-up and temperature-time plateau region programs depicted in Figure 1, respectively) exhibited the presence of a diffraction peak at $2 \theta \sim 32.3^{\circ}$ that can be assigned to a monoclinic silver oxide (AgO) phase (JCPDS file No. 74-1743 [81]) (see Figures 11c and 12c, respectively). In fact, it has been reported that the silver oxide layer covering Ag NPs is formed at surface level during the annealing process, and as expected from a thermodynamic and kinetic point of view, the higher the annealing temperature $\mathrm{T}_{\mathrm{A}}$, and the longer the annealing time, $\mathrm{t}_{\mathrm{A}}$, the higher the degree of oxidation in the samples [38,57,82]. As mentioned above, this silver oxide phase is only present as a surface layer around the formed silver nanoparticles, which will be discussed further.

\subsection{Faceting of the Dewetted Nanostructures and Micro-Cristallinity}

As a result of the SSD process, the formed Ag NPs particles show an almost spherical shape (planar size vertical size) and, additionally, equilibrium facets can be seen on the surface of them. In the synthesis and application of metallic nanostructures, crystallographic nanostructure faceting plays a crucial role $[31,58]$. The capacity to grow specific facets while eliminating others is largely the route by which nanostructures are shape-engineered [31,58]. Among the different SSD stages, the final one, in which irregularly shaped islands are reorganized into more favorable configurations, is essential in terms of determining nanostructure faceting $[31,58]$. In the case of freestanding metal nanostructures, the shape that minimizes the surface energy is commonly referred to as the Wulff shape $[31,47,58,83]$. However, when formed on a low-surface energy substrate, the nanostructure equilibrium shape still resembles the Wulff shape, but there, it is truncated by the substrate surface (for convenience, this will also be referred to as the Wulff shape) $[31,47,58,83]$. Figure $13 a-d$ show high-magnification FE-SEM micrograph images of typical Ag NPs (formed under different SSD process parameters as indicated), which appear highly faceted and show 
a Wulff-like shape. It can be clearly seen that the Ag NPs exposed the $\{111\}$ facets while facing up (see Figure 13a), with the Ag nanostructures orientated with their [111] axis perpendicular to the glass substrate surface (please see the procedure followed to assign the Miller indices to the exposed facets of the formed silver nanoparticles in SI). This is in agreement with the XRD results presented above, indicating out-of-plane [111] texturing. Furthermore, the Ag NPs exposed the co-presence of $\{111\},\{110\}$, and $\{100\}$ equilibrium facet characteristics (see Figure 13a-d), which can be attributed to a 26-facet rhombicuboctahedron crystal shape [84-86]. In fact, the most common equilibrium configuration for a face-centered-cubic (fcc) metal is a cuboctahedron with six (100) facets and eight (111) facets, which result from a surface energy hierarchy of $\gamma_{111}<\gamma_{100}<\gamma_{110}[58,83,86]$.

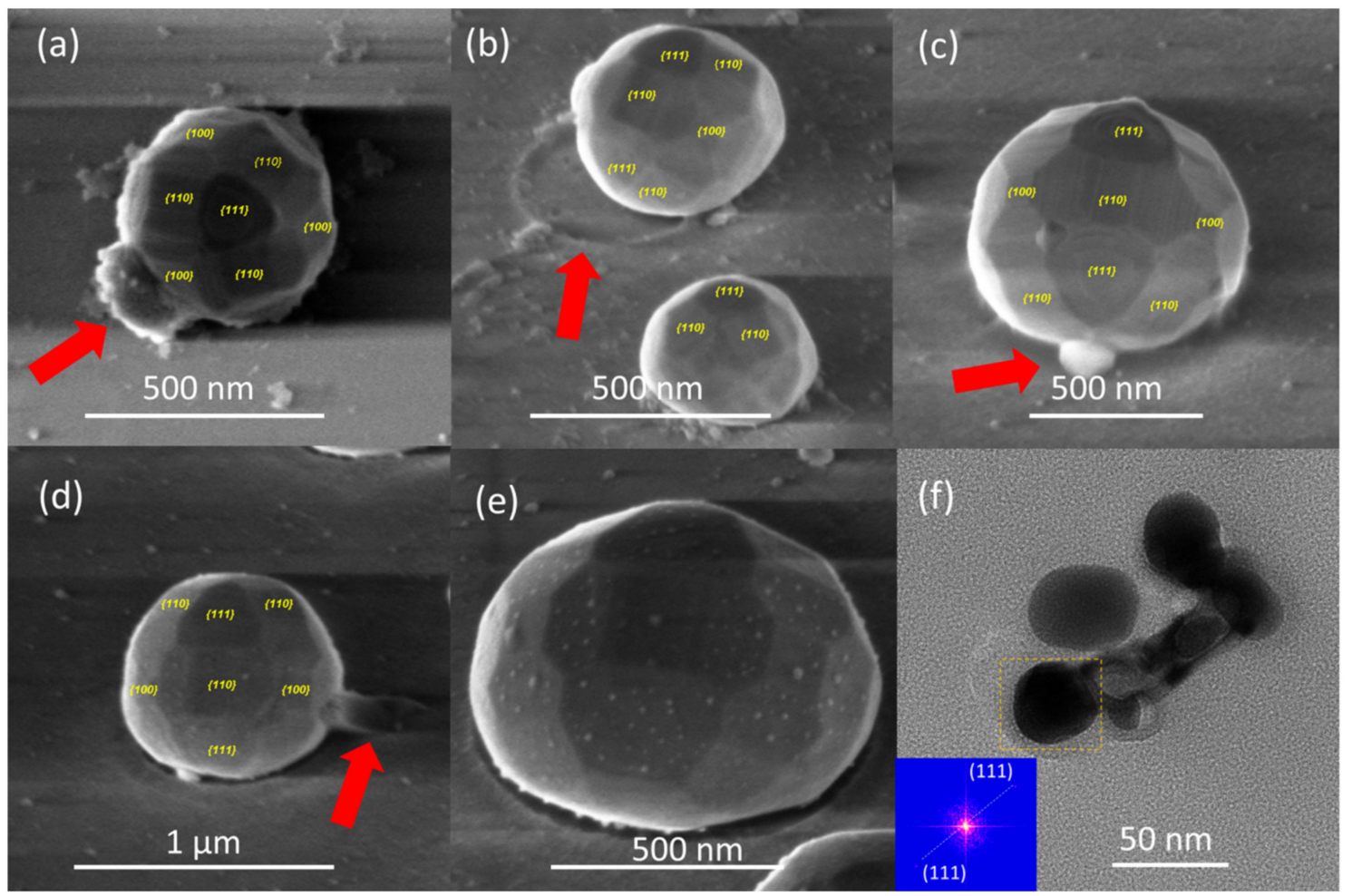

Figure 13. (a-e) Representative FE-SEM micrograph images of different Ag nanoparticles obtained by the solid-state thermal dewetting process. (a) top- and (b-e) tilted-view images to show the different low-index facets to highlight various features. (f) Representative HR-TEM micrograph image of silver nanoparticles obtained by the SSD process. Inset of (f) shows the FFT pattern extracted from the HR-TEM micrograph of the Ag NP enclosed by a yellow dashed rectangle in panel (f). Samples depicted in $(\mathbf{a}-\mathbf{c}, \mathbf{f})$ have been obtained by applying the constant temperature region program depicted in Figure 1 with the following SSD process parameters: (a) $d_{A g}=40 \mathrm{~nm}, \mathrm{~T}_{\mathrm{A}}=450{ }^{\circ} \mathrm{C}$, $\mathrm{t}_{\mathrm{A}}=51 \mathrm{~min} ;(\mathbf{b}) \mathrm{d}_{\mathrm{Ag}}=40 \mathrm{~nm}, \mathrm{~T}_{\mathrm{A}}=450{ }^{\circ} \mathrm{C}, \mathrm{t}_{\mathrm{A}}=17 \mathrm{~min} ;(\mathbf{c}) \mathrm{d}_{\mathrm{Ag}}=80 \mathrm{~nm}, \mathrm{~T}_{\mathrm{A}}=500{ }^{\circ} \mathrm{C}, \mathrm{t}_{\mathrm{A}}=60 \mathrm{~min} ;$ and $(\mathbf{f}) \mathrm{d}_{\mathrm{Ag}}=80 \mathrm{~nm}, \mathrm{~T}_{\mathrm{A}}=500{ }^{\circ} \mathrm{C}, \mathrm{t}_{\mathrm{A}}=17 \mathrm{~min}$. The samples shown in (d,e) were obtained by applying the heat-up region program depicted in Figure 1 with the following SSD process parameters: $\mathrm{d}_{\mathrm{Ag}}=80 \mathrm{~nm}$ and $\mathrm{T}_{\mathrm{A}}=450{ }^{\circ} \mathrm{C}$.

Furthermore, the high-magnification FE-SEM micrograph images depicted in Figure 13a-e highlight features of both the SSD process leading to the formation of the Ag NPs and the formed dewetted Ag nanoparticles themselves. The first example is depicted in Figure $13 a-d$, in each micrograph image, the red arrow indicates a specific feature. During the SSD process, mass transfer from the connecting filament to the particles and until complete filament rupture occurs; in Figure 13a and in Figure 13c, the arrows indicate the residual signatures of the original retracted filament from which the particle originated In addition, the red arrows in Figure 13b,d indicate the residual trace marks of the mass 
transfer on the glass substrate towards one of the Ag nanoparticles. Figure 13e shows a high-magnification FE-SEM micrograph image of a silver nanoparticle decorated by very tiny silver nanoparticles, which can be attributed to the last stages of the Ostwald ripening growth mechanism.

The finer details of the microstructure of the silver nanoparticles were further investigated by high resolution transmission electron microscopy (HR-TEM), which is illustrated in Figure 13f. The Inset of Figure $13 \mathrm{f}$ shows the fast Fourier transform (FFT) image of the marked zone of the Ag NP depicted in Figure 13f, demonstrating the high-quality single crystalline nature of this nanoparticle, which corresponds to cubic silver (111) crystallographic planes.

\subsection{Surface Chemical Analysis of the Ag Nanoparticle Arrays}

Ag experiences oxidation when exposed to air. Jing et al. [87] studied the oxidation of Ag films when they are annealed in air and determined that films annealed at temperatures below $300^{\circ} \mathrm{C}$ are not oxidized and that the $\mathrm{Ag}$ becomes oxidized at temperatures higher than $350{ }^{\circ} \mathrm{C}$. The decomposition of the $\mathrm{Ag}$ oxide at $300{ }^{\circ} \mathrm{C}$ was studied by Herly and Prout [88]. The Ag oxide layer covering the Ag nanoparticles is formed as a surface passivation layer during the annealing process [38], AgO is expected to be less stable than $\mathrm{Ag}_{2} \mathrm{O}$, and it decomposes according to the following reaction [89]:

$$
4 \mathrm{AgO} \leftrightharpoons 2 \mathrm{Ag}_{2} \mathrm{O}+\mathrm{O}_{2}
$$

As such in order to study the exact surface chemistry of the evolution of the as-grown silver layers before and after the formation of the Ag NPs through the SSD process, the Xray photoelectron spectroscopy (XPS) surface analysis technique was employed. Figure 14 shows the evolution of high-resolution XPS Ag 3d and Ag MNN spectra regions for a vacuum-thermal-evaporated silver layer with a nominal thickness $d_{A g}=80 \mathrm{~nm}$ for the as-grown silver layers and after the annealing step of the SSD process applying the constant temperature region program depicted in Figure 1 at $T_{A}=500{ }^{\circ} \mathrm{C}$ and for $t_{A}=26 \mathrm{~min}$. The silver oxides show an anomalous negative binding energy shift compared to the metal with binding energies and Auger parameter values for $\mathrm{Ag}_{2} \mathrm{O}$ and $\mathrm{AgO}$ that are quite similar, making it quite difficult to determine the species of the oxides. For $\mathrm{Ag}_{2} \mathrm{O}$ and $\mathrm{AgO}$ the binding energy shifts from metallic $\mathrm{Ag}$ are approximately $-0.4 \mathrm{eV}$ and $-0.8 \mathrm{eV}$ [90]. The XPS Ag 3d region was deconvoluted for the Ag and Ag oxides contributions that were fixed to $\mathrm{Ag} 3 \mathrm{~d}_{5 / 2}$ at the binding energies of $368.2 \mathrm{eV}$ (full width at half maximum (FWHM) $1.12 \mathrm{eV}$ ), $368.3 \mathrm{eV}$ (FWHM 1.20), and $367.8 \mathrm{eV}$ (FWHM $1.25 \mathrm{eV}$ ) for $\mathrm{Ag}$, $\mathrm{Ag}_{2} \mathrm{O}$, and $\mathrm{AgO}$, respectively [89-91]. A FWHM for AgO ranging from 1.2 to 1.6 has been proposed for $\mathrm{Ag} 3 \mathrm{~d}_{5 / 2}$ [91,92]. The separation between $\mathrm{Ag} 3 \mathrm{~d}_{5 / 2}$ and $\mathrm{Ag} 3 \mathrm{~d}_{3 / 2}$ was $6 \mathrm{eV}$. The O1s region sample was not useful for determining the oxygen proportion of the oxide because of the surface contamination and the contribution of the substrate. However, the Auger parameters allowed us to confirm the presence of oxides in the outer layer of the Ag particles.

Through the above experiments we concluded that the silver layer obtained at the surface was AgO (Auger parameter of $724.8 \mathrm{eV}$ ) and metallic silver after $1 \mathrm{~min}$ of etching with $\mathrm{Ar}^{+} 4 \mathrm{kV}$ (Auger parameter of $726.2 \mathrm{eV}$ ). Figure 14 shows also the XPS Ag MNN region; the two most intense peaks in the Auger structure the oxidized forms of the Ag and the reduced one, $\mathrm{M}_{4} \mathrm{~N}_{45} \mathrm{~N}_{45}$, to be distinguished from each other based on the kinetic energy value of $357.9 \mathrm{eV}$ for the reduced form and $356.9 \mathrm{eV}$ for the oxidized form [90]. Both oxides show similar XPS MNN spectra patterns, and their patterns are well-differentiated from that of MNN for metallic silver [89]. The sample submitted to the SSD process for $t_{A}=26$ min exhibited a deeper oxidized state (see Figure 14a,b). The amount of silver oxide in the outer surface layers of the Ag NPs increased with the annealing time, which was corroborated by the fact that the AgO phase was detected by XRD for a sample with an annealing time of $60 \mathrm{~min}$ (see Figure 12). 

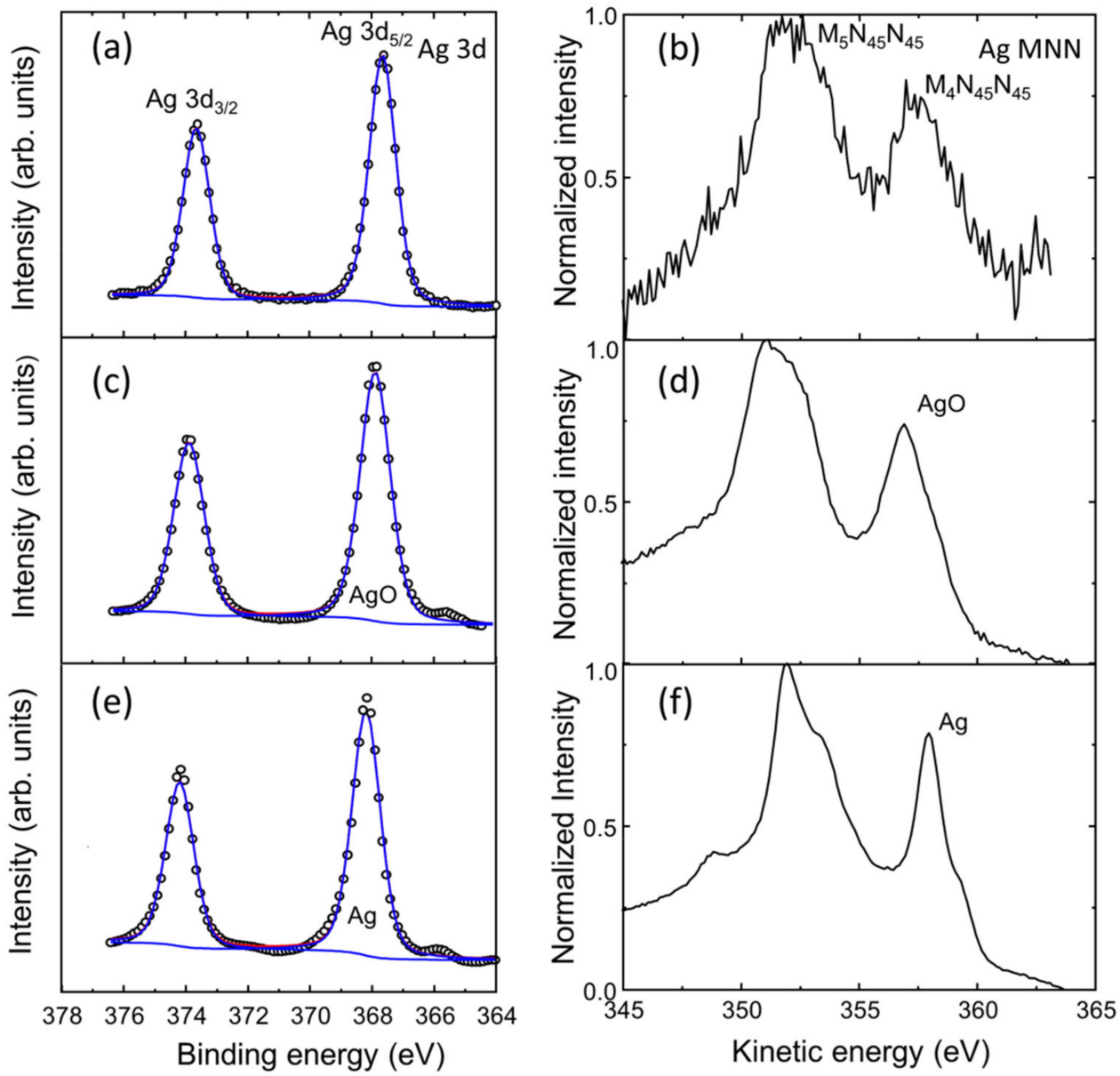

Figure 14. Evolution of high-resolution XPS Ag 3d and Ag MNN region spectra for a vacuumthermal-evaporated silver layer with a nominal thickness $d_{A g}=80 \mathrm{~nm}$. (a,b) Surface study of the sample after the annealing step during the SSD process applying the constant temperature region program depicted in Figure 1 at $\mathrm{T}_{\mathrm{A}}=500{ }^{\circ} \mathrm{C}$ and for $\mathrm{t}_{\mathrm{A}}=26 \mathrm{~min}$. Surface analysis of a silver layer with a nominal thickness $\mathrm{d}_{\mathrm{Ag}}=80 \mathrm{~nm}$ as-grown (without annealing): (c,d) and (e,f) before and after 1 min surface bombardment with $\mathrm{Ar}^{+}(\sim 5 \mathrm{~nm} / \mathrm{min}$ etching rate), respectively. Experimental data are presented by small open circles, while superimposed solid lines are the result of peak-fitting reconstruction.

\section{Conclusions}

In this work, silver nanoparticle arrays on glass substrates were obtained by a solidstate thermal dewetting process for vacuum-evaporated polycrystalline silver precursor layers. The thermal treatment promoted the morphological modification of the films, leading to the Ag NPs having a discrete structure. The silver size, shape, surface density, and inter-nanoparticle distance of the nanoparticles was dependent on the initial film thickness, annealing temperature, and annealing time. Additionally, the shape of the NPs evolved from elongated at lower temperatures to circular as the temperature increased, and at longer annealing times, the circularity diminished slightly. The quasi-periodic nature of the $\mathrm{Ag}$ NPs arrays was quantified at length scales ranging from 0.9 to 2.8 micrometers. The Ag nanoparticles exhibited a cubic silver structure with (111) as the preferred crystallographic orientation. The presence of a monoclinic silver oxide phase was identified in samples annealed at the highest studied annealing temperatures and annealing times. Faceted Ag NPs were obtained with a 26-facet rhombicuboctahedron crystal shape, exposing the co-presence of the equilibrium facet characteristics of $\{111\},\{110\}$, and $\{100\}$. Through XPS surface analysis, the presence $\mathrm{AgO}$ on the surface around the silver nanoparticles that was synthesized at the highest assayed temperature was detected. In conclusion, this 
work paves the way for the design and synthesis of silver nanoparticle arrays for further applications in engineering plasmonics in optical, electronic, and catalytic systems.

Supplementary Materials: The following supporting information can be downloaded at: https: / / www.mdpi.com/article/10.3390/nano12040617/s1, Figure S1: FE-SEM micrographs and silver nanoparticle size distribution histograms for vacuum-thermal-evaporated silver layers with a nominal thickness $d_{A g}=40 \mathrm{~nm}$ at different stages of the annealing step of the SSD process applying the heat-up region program depicted in Figure 1 and ending at different $\mathrm{T}_{\mathrm{A}}$ values as indicated. Figure S2: FE-SEM micrographs and silver nanoparticle size distribution histograms for vacuum-thermal-evaporated silver layers with a nominal thickness $\mathrm{d}_{\mathrm{Ag}}=80 \mathrm{~nm}$ at different stages of the annealing step of the SSD process applying the heat-up region program depicted in Figure 1 and ending at different $\mathrm{T}_{\mathrm{A}}$ values as indicated. Figure S3: Typical normalized measured radially averaged autocorrelation function, $g(r)$, for the silver nanoparticle positions for typical samples with $d_{A g}=40 \mathrm{~nm}$ and different $T_{A}$ values, as indicated. Figure S4: Typical normalized and radially measured averaged autocorrelation function, $g(r)$, for the silver nanoparticle positions for typical samples with $\mathrm{d}_{\mathrm{Ag}}=80 \mathrm{~nm}$ and different $\mathrm{T}_{\mathrm{A}}$ values, as indicated. Figure S5: Top view of FE-SEM micrographs $\mathrm{t}$ and silver nanoparticle size distribution histograms of vacuum-thermal-evaporated silver layers with a nominal thickness $\mathrm{d}_{\mathrm{Ag}}=40 \mathrm{~nm}$ at different stages of the annealing step of the SSD process by applying the constant temperature region program depicted in Figure 1 at $\mathrm{T}_{\mathrm{A}}=450{ }^{\circ} \mathrm{C}$ and ending at different $\mathrm{t}_{\mathrm{A}}$ values, as indicated. Figure S6: Top views of FE-SEM micrographs and silver nanoparticle size distribution histograms of vacuum-thermal-evaporated silver layers with a nominal thickness $d_{A g}=80 \mathrm{~nm}$ at different stages of the annealing step of the SSD process by applying the constant temperature region program depicted in Figure 1 at $\mathrm{T}_{\mathrm{A}}=500{ }^{\circ} \mathrm{C}$ and ending at different $\mathrm{t}_{\mathrm{A}}$ values, as indicated. Figure S7: Plot of silver nanoparticle average size (D) square as a function of the annealing time $t_{A}$ of the annealing step of the SSD process. Figure S8: FE-SEM micrograph images of vacuum-thermalevaporated silver layers with four nominal thickness values: (a) $d_{A g}=20 \mathrm{~nm}$, (b) $40 \mathrm{~nm}$, (c) $60 \mathrm{~nm}$, and (d) $80 \mathrm{~nm}$ annealed at $\mathrm{T}_{\mathrm{A}}=400{ }^{\circ} \mathrm{C}$ (applying the temperature-time plateau region program depicted in Figure 1) with $t_{A}=1 \mathrm{~h}$. Structural parameter definitions are also given: the texture coefficient $\mathrm{TC}(h k l)$ and the Scherrer equation applied to the calculation is the crystallite coherent scattering domain. The procedure used to determine surface crystallography of the faceted silver nanoparticles is also provided.

Author Contributions: Conceptualization, J.A.B., D.A., R.H. and E.A.D.; methodology, J.A.B., D.A. and E.A.D.; investigation, J.A.B., E.N.-A., R.H. and F.M.J.; resources, J.A.B., D.A. and E.A.D.; data curation, J.R.R.-B., D.A. and E.A.D.; writing—original draft preparation, J.A.B., D.A., E.N.-A., F.M.J., R.H. and E.A.D.; writing-review and editing, E.A.D. and J.R.R.-B.; supervision, E.A.D. and D.A.; funding acquisition, E.A.D., E.N.-A., R.H. and J.R.R.-B. All authors have read and agreed to the published version of the manuscript.

Funding: This research was funded by CSIC (Comisión Sectorial de Investigación Científica) of the Universidad de la República, in Montevideo, Uruguay, PEDECIBA—Física, Uruguay. DI Consolidado 039.361/2019 PUCV Project, Valparaíso, Chile. Junta de Andalucía of Spain through the projects UMA18-FEDERJA-041 and UMA18-FEDERJA-039. The APC was funded by PEDECIBA-Física, Uruguay. DI Consolidado 039.361/2019 PUCV Project, Valparaíso, Chile. Junta de Andalucía of Spain through the projects UMA18-FEDERJA-041 and UMA18-FEDERJA-039.

Institutional Review Board Statement: Not applicable.

Informed Consent Statement: Not applicable.

Data Availability Statement: Not applicable.

Acknowledgments: This work was supported by CSIC (Comisión Sectorial de Investigación Científica) of the Universidad de la República, in Montevideo, Uruguay, PEDECIBA-Física, Uruguay. The Authors are grateful to Junta de Andalucia (Spain) through the research projects UMA18-FEDERJA041 and UMA18-FEDERJA-039, and also to Universidad de Málaga through the project B1-2020/08. R.H. thanks the support received in the framework of DI Consolidado 039.361/2019 PUCV Project, Valparaíso, Chile. The authors are also grateful to Ministerio de Ciencia e Innovación, Spain, through the research project PID2020-117832RB-I00.

Conflicts of Interest: The authors declare no conflict of interest. 


\section{References}

1. Lin, H.K.; Huang, C.W.; Lin, Y.H.; Chuang, W.S.; Huang, J.C. Effects of Accumulated Energy on Nanoparticle Formation in Pulsed-Laser Dewetting of AgCu Thin Films. Nanoscale Res. Lett. 2021, 16, 110. [CrossRef]

2. Wang, L.; Hasanzadeh Kafshgari, M.; Meunier, M. Optical Properties and Applications of Plasmonic-Metal Nanoparticles. Adv. Funct. Mater. 2020, 30, 2005400. [CrossRef]

3. Pandey, P.; Sui, M.; Zhang, Q.; Li, M.-Y.; Kunwar, S.; Lee, J. Systematic control of the size, density and configuration of Pt nanostructures on sapphire (0001) by the variation of deposition amount and dwelling time. Appl. Surf. Sci. 2016, 368, 198-207. [CrossRef]

4. Torrisi, V.; Censabella, M.; Piccitto, G.; Compagnini, G.; Grimaldi, M.G.; Ruffino, F. Characteristics of Pd and Pt Nanoparticles Produced by Nanosecond Laser Irradiations of Thin Films Deposited on Topographically-Structured Transparent Conductive Oxides. Coatings 2019, 9, 68. [CrossRef]

5. Wani, I.A. Review-Recent Advances in Biogenic Silver Nanoparticles \& NanoComposite Based Plasmonic-Colorimetric and Electrochemical Sensors. ECS J. Solid State Sci. Technol. 2021, 10, 47003. [CrossRef]

6. Kunwar, S.; Sui, M.; Zhang, Q.; Pandey, P.; Li, M.-Y.; Lee, J. Various Silver Nanostructures on Sapphire Using Plasmon SelfAssembly and Dewetting of Thin Films. Nano-Micro Lett. 2016, 9, 17. [CrossRef] [PubMed]

7. Loiseau, A.; Asila, V.; Boitel-Aullen, G.; Lam, M.; Salmain, M.; Boujday, S. Silver-Based Plasmonic Nanoparticles for and Their Use in Biosensing. Biosensors 2019, 9, 78. [CrossRef]

8. Moores, A.; Goettmann, F. The plasmon band in noble metal nanoparticles: An introduction to theory and applications. New J. Chem. 2006, 30, 1121-1132. [CrossRef]

9. Taylor, A.B.; Zijlstra, P. Single-Molecule Plasmon Sensing: Current Status and Future Prospects. ACS Sens. 2017, 2, 1103-1122. [CrossRef]

10. Pandey, P.; Kunwar, S.; Sui, M.; Zhang, Q.; Li, M.; Lee, J. Morphological and Optical Evolution of Silver Nanoparticles on Sapphire (0001) Along with the Concurrent Influence of Diffusion, Ostwald's Ripening, and Sublimation. IEEE Trans. Nanotechnol. 2017, 16, 321-332. [CrossRef]

11. Pandey, P.; Kunwar, S.; Sui, M.; Bastola, S.; Lee, J. Investigation on the morphological and optical evolution of bimetallic Pd-Ag nanoparticles on sapphire (0001) by the systematic control of composition, annealing temperature and time. PLoS ONE 2017, 12, e0189823. Available online: https:/ /journals.plos.org/plosone/article?id=10.1371/journal.pone.0189823 (accessed on 20 January 2022). [CrossRef] [PubMed]

12. Łapiński, M.; Kozioł, R.; Cymann, A.; Sadowski, W.; Kościelska, B. Substrate Dependence in the Formation of Au Nanoislands for Plasmonic Platform Application. Plasmonics 2020, 15, 101-107. [CrossRef]

13. Liu, X.; Li, D.; Sun, X.; Li, Z.; Song, H.; Jiang, H.; Chen, Y. Tunable Dipole Surface Plasmon Resonances of Silver Nanoparticles by Cladding Dielectric Layers. Sci. Rep. 2015, 5, 12555. [CrossRef] [PubMed]

14. Chaudhari, K.; Ahuja, T.; Murugesan, V.; Subramanian, V.; Ganayee, M.A.; Thundat, T.; Pradeep, T. Appearance of SERS activity in single silver nanoparticles by laser-induced reshaping. Nanoscale 2019, 11, 321-330. [CrossRef]

15. Razek, S.A.; Ayoub, A.B.; Swillam, M.A. One Step Fabrication of Highly Absorptive and Surface Enhanced Raman Scattering (SERS) Silver Nano-trees on Silicon Substrate. Sci. Rep. 2019, 9, 13588. [CrossRef] [PubMed]

16. Mauriz, E.; Lechuga, L.M. Plasmonic Biosensors for Single-Molecule Biomedical Analysis. Biosensors 2021, 11, 123. [CrossRef]

17. Ko, Y.H.; Yu, J.S. Silver nanoparticle decorated ZnO nanorod arrays on AZO films for light absorption enhancement. Phys. Status Solidi 2012, 209, 297-301. [CrossRef]

18. Ivanova, T.; Harizanova, A.; Koutzarova, T.; Vertruyen, B. Optical and structural characterization of $\mathrm{TiO}_{2}$ films doped with silver nanoparticles obtained by sol-gel method. Opt. Mater. 2013, 36, 207-213. [CrossRef]

19. Tanyeli, I.; Nasser, H.; Es, F.; Bek, A.; Turan, R. Effect of surface type on structural and optical properties of Ag nanoparticles formed by dewetting. Opt. Express 2013, 21, A798-A807. [CrossRef]

20. Santbergen, R.; Temple, T.L.; Liang, R.; Smets, A.H.M.; van Swaaij, R.A.C.M.M.; Zeman, M. Application of plasmonic silver island films in thin-film silicon solar cells. J. Opt. 2012, 14, 24010. [CrossRef]

21. Catchpole, K.R.; Polman, A. Design principles for particle plasmon enhanced solar cells. Appl. Phys. Lett. 2008, 93, 191113. [CrossRef]

22. Khodashenas, B.; Ghorbani, H.R. Synthesis of silver nanoparticles with different shapes. Arab. J. Chem. 2019, 12, 1823-1838. [CrossRef]

23. García-Barrasa, J.; López-de-Luzuriaga, J.; Monge, M. Silver nanoparticles: Synthesis through chemical methods in solution and biomedical applications. Open Chem. 2011, 9, 7-19. [CrossRef]

24. Botasini, S.; Dalchiele, E.A.; Benech, J.C.; Méndez, E. Stabilization of triangular and heart-shaped plane silver nanoparticles using 2-thiobarbituric acid. J. Nanoparticle Res. 2011, 13, 2819-2828. [CrossRef]

25. Le Bris, A.; Maloum, F.; Teisseire, J.; Sorin, F. Self-organized ordered silver nanoparticle arrays obtained by solid state dewetting Appl. Phys. Lett. 2014, 105, 203102. [CrossRef]

26. Chaika, A.N.; Bozhko, S.I.; Ionov, A.M.; Sveklo, I.; Postnova, E.Y.; Semenov, V.N.; Bisht, A.; Rabkin, E. The role of defects in solid state dewetting of ultrathin Ag film on Si(557). Scr. Mater. 2021, 194, 113655. [CrossRef]

27. Oh, H.; Pyatenko, A.; Lee, M. A hybrid dewetting approach to generate highly sensitive plasmonic silver nanoparticles with a narrow size distribution. Appl. Surf. Sci. 2021, 542, 148613. [CrossRef] 
28. Ye, J.; Zuev, D.; Makarov, S. Dewetting mechanisms and their exploitation for the large-scale fabrication of advanced nanophotonic systems. Int. Mater. Rev. 2019, 64, 439-477. [CrossRef]

29. Cho, J.S.; Jang, W.; Park, K.H.; Wang, D.H. A gold nanodot array imprinting process based on solid-state dewetting for efficient oxide-free photovoltaic devices. Appl. Phys. Lett. 2020, 117, 171601. [CrossRef]

30. Ruffino, F.; Grimaldi, M.G. Atomic force microscopy study of the growth mechanisms of nanostructured sputtered Au film on Si(111): Evolution with film thickness and annealing time. J. Appl. Phys. 2010, 107, 104321. [CrossRef]

31. Ruffino, F.; Grimaldi, M.G. Nano-shaping of gold particles on silicon carbide substrate from solid-state to liquid-state dewetting Surf. Interfaces 2021, 24, 101041. [CrossRef]

32. Schulte, J. Nanotechnology: Global Strategies, Industry Trends and Applications; Schulte, J., Ed.; John Wiley \& Sons, Ltd.: Chichester, UK, 2005.

33. Kumar, N.; Alam, F.; Dutta, V. Deposition of Ag and Au-Ag alloy nanoparticle films by spray pyrolysis technique with tuned plasmonic properties. J. Alloys Compd. 2014, 585, 312-317. [CrossRef]

34. Badán, J.A.; Navarrete-Astorga, E.; Henríquez, R.; Martín, F.; Marotti, R.E.; Ramos-Barrado, J.R.; Dalchiele, E.A. Optical properties of silver nanoparticles deposited onto silicon substrates by different soft-solution processing techniques. Opt. Mater. 2020, 100, 109651. [CrossRef]

35. Raffi, M.; Akhter, J.I.; Hasan, M.M. Effect of annealing temperature on Ag nano-composite synthesized by sol-gel. Mater. Chem. Phys. 2005, 99, 405-409. [CrossRef]

36. Berni, M.; Carrano, I.; Kovtun, A.; Russo, A.; Visani, A.; Dionigi, C.; Liscio, A.; Valle, F.; Gambardella, A. Monitoring morphological and chemical properties during silver solid-state dewetting. Appl. Surf. Sci. 2019, 498, 143890. [CrossRef]

37. Wang, D.; Ji, R.; Schaaf, P. Formation of precise 2D Au particle arrays via thermally induced dewetting on pre-patterned substrates. Beilstein J. Nanotechnol. 2011, 2, 318-326. [CrossRef]

38. Serrano, A.; Llorca-Hernando, O.; del Campo, A.; Rubio-Marcos, F.; Rodríguez de la Fuente, O.; Fernández, J.F.; García, M.A. Ag-AgO nanostructures on glass substrates by solid-state dewetting: From extended to localized surface plasmons. J. Appl. Phys. 2018, 124, 133103. [CrossRef]

39. Lin, Y.-H.; Wang, J.-J.; Wang, Y.-T.; Lin, H.-K.; Lin, Y.-J. Antifungal Properties of Pure Silver Films with Nanoparticles Induced by Pulsed-Laser Dewetting Process. Appl. Sci. 2020, 10, 2260. [CrossRef]

40. Badán, J.A.; Jauregui, G.; Navarrete-Astorga, E.; Henríquez, R.; Jiménez, F.M.; Ariosa, D.; Dalchiele, E.A. Solid-state thermal dewetted silver nanoparticles onto electrochemically grown self-standing vertically aligned ZnO nanorods for three-dimensional plasmonic nanostructures. Ceram. Int. 2021, 47, 32685. [CrossRef]

41. Araújo, A.; Mendes, M.J.; Mateus, T.; Vicente, A.; Nunes, D.; Calmeiro, T.; Fortunato, E.; Águas, H.; Martins, R. Influence of the Substrate on the Morphology of Self-Assembled Silver Nanoparticles by Rapid Thermal Annealing. J. Phys. Chem. C 2016, 120, 18235-18242. [CrossRef]

42. Herre, P.; Will, J.; Dierner, M.; Wang, D.; Yokosawa, T.; Zech, T.; Wu, M.; Przybilla, T.; Romeis, S.; Unruh, T.; et al. Rapid fabrication and interface structure of highly faceted epitaxial Ni-Au solid solution nanoparticles on sapphire. Acta Mater. 2021, 220 , 117318. [CrossRef]

43. Serrano, A.; Rubio-Zuazo, J.; López-Sánchez, J.; Enríquez, E.; Salas-Cólera, E.; Castro, G.R. Nanostructured Au(111)/Oxide Epitaxial Heterostructures with Tailoring Plasmonic Response by a One-Step Strategy. J. Phys. Chem. C 2019, 123, $25294-25302$. [CrossRef]

44. Choi, M.; Kang, G.; Shin, D.; Barange, N.; Lee, C.-W.; Ko, D.-H.; Kim, K. Lithography-Free Broadband Ultrathin-Film Absorbers with Gap-Plasmon Resonance for Organic Photovoltaics. ACS Appl. Mater. Interfaces 2016, 8, 12997-13008. [CrossRef] [PubMed]

45. Jacquet, P.; Podor, R.; Ravaux, J.; Lautru, J.; Teisseire, J.; Gozhyk, I.; Jupille, J.; Lazzari, R. On the solid-state dewetting of polycrystalline thin films: Capillary versus grain growth approach. Acta Mater. 2018, 143, 281-290. [CrossRef]

46. Gentili, D.; Foschi, G.; Valle, F.; Cavallini, M.; Biscarini, F. Applications of dewetting in micro and nanotechnology. Chem. Soc. Rev. 2012, 41, 4430-4443. [CrossRef] [PubMed]

47. Thompson, C.V. Solid-State Dewetting of Thin Films. Annu. Rev. Mater. Res. 2012, 42, 399-434. [CrossRef]

48. Jacquet, P.; Podor, R.; Ravaux, J.; Teisseire, J.; Gozhyk, I.; Jupille, J.; Lazzari, R. Grain growth: The key to understand solid-state dewetting of silver thin films. Scr. Mater. 2016, 115, 128-132. [CrossRef]

49. Pandey, P.; Kunwar, S.; Sui, M.; Li, M.-Y.; Zhang, Q.; Lee, J. Effect of annealing temperature on morphological and optical transition of silver nanoparticles on c-plane sapphire. J. Nanosci. Nanotechnol. 2018, 18, 3466-3477. [CrossRef]

50. Yadavali, S.; Kalyanaraman, R. Fabricating Metal Nanostructures with pulsed laser dewetting self-assembly. Adv. Mater. Process. 2013, 171, 22-26.

51. Hu, X.; Cahill, D.G.; Averback, R.S. Nanoscale pattern formation in Pt thin films due to ion-beam-induced dewetting. Appl. Phys. Lett. 2000, 76, 3215-3217. [CrossRef]

52. Hu, X.; Cahill, D.G.; Averback, R.S. Dewetting and nanopattern formation of thin Pt films on SiO 2 induced by ion beam irradiation. J. Appl. Phys. 2001, 89, 7777-7783. [CrossRef]

53. Hu, X.; Cahill, D.G.; Averback, R.S. Burrowing of Pt nanoparticles into $\mathrm{SiO}_{2}$ during ion-beam irradiation. J. Appl. Phys. 2002, 92, 3995-4000. [CrossRef]

54. Hu, X.; Cahill, D.G.; Averback, R.S.; Birtcher, R.C. In situ transmission electron microscopy study of irradiation induced dewetting of ultrathin Pt films. J. Appl. Phys. 2002, 93, 165-169. [CrossRef] 
55. Kojima, Y.; Kato, T. Nanoparticle formation in Au thin films by electron-beam-induced dewetting. Nanotechnology 2008, $19,255605$. [CrossRef]

56. Rusciano, G.; Capaccio, A.; Martinez, A.; Sasso, A. Nanoporous silver films produced by solid-state dewetting for SERS applications. In Proceedings of the SPIE, Online, 18 April 2021; Volume 11772, p. 117720E.

57. Toropov, N.A.; Leonov, N.B.; Vartanyan, T.A. Influence of Silver Nanoparticles Crystallinity on Localized Surface Plasmons Dephasing Times. Phys. Status Solidi 2018, 255, 1700174. [CrossRef]

58. Preston, A.S.; Hughes, R.A.; Demille, T.B.; Davila, V.M.R.; Neretina, S. Dewetted nanostructures of gold, silver, copper, and palladium with enhanced faceting. Acta Mater. 2019, 165, 15-25. [CrossRef]

59. Kosinova, A.; Klinger, L.; Kovalenko, O.; Rabkin, E. The role of grain boundary sliding in solid-state dewetting of thin polycrystalline films. Scr. Mater. 2014, 82, 33-36. [CrossRef]

60. Leroy, F.; Borowik, Ł.; Cheynis, F.; Almadori, Y.; Curiotto, S.; Trautmann, M.; Barbé, J.C.; Müller, P. How to control solid state dewetting: A short review. Surf. Sci. Rep. 2016, 71, 391-409. [CrossRef]

61. Ding, Y.; Fan, F.; Tian, Z.; Wang, Z.L. Sublimation-Induced Shape Evolution of Silver Cubes. Small 2009, 5, 2812-2815. [CrossRef]

62. Morawiec, S.; Mendes, M.J.; Mirabella, S.; Simone, F.; Priolo, F.; Crupi, I. Self-assembled silver nanoparticles for plasmon-enhanced solar cell back reflectors: Correlation between structural and optical properties. Nanotechnology 2013, 24, 265601. [CrossRef]

63. Yoo, J.; Kim, J.-H.; Lee, K.; Lee, S.; Kim, S.; Park, H.-K.; Kim, S.-W.; Bae, J.; Park, J.-J.; Choi, D. Dewetted gold nanoparticles on $\mathrm{ZnO}$ nanorods for three-dimensionally distributed plasmonic hot spots. Scr. Mater. 2013, 69, 654-657. [CrossRef]

64. Saritas, S.; Özen, E.S.; Aydinli, A. Laser induced spinodal dewetting of Ag thin films forphotovoltaic applications. J. Optoelectron. Adv. Mater. 2013, 15, 10-13.

65. Oliva-Ramirez, M.; Schade, P.; Zobel, C.; Wang, D.; Schaaf, P. Morphological and compositional mapping of supersaturated AuNi alloy nanoparticles fabricated by solid state dewetting. Appl. Surf. Sci. Adv. 2021, 4, 100082. [CrossRef]

66. Hamm, G.; Becker, C.; Henry, C.R. Bimetallic Pd-Au nanocluster arrays grown on nanostructured alumina templates. Nanotechnology 2006, 17, 1943-1947. [CrossRef]

67. Paredes-Arroyo, C.; Guzmán, R. Nonequilibrium molecular dynamics simulation of a dense confined nanofluid: Wall-nanoparticle interaction effects. Comput. Mater. Sci. 2017, 131, 11-20. [CrossRef]

68. Sudheer; Mondal, P.; Rai, V.N.; Srivastava, A.K. A study of growth and thermal dewetting behavior of ultra-thin gold films using transmission electron microscopy. AIP Adv. 2017, 7, 75303. [CrossRef]

69. Simonsen, S.B.; Chorkendorff, I.; Dahl, S.; Skoglundh, M.; Sehested, J.; Helveg, S. Direct Observations of Oxygen-induced Platinum Nanoparticle Ripening Studied by In Situ TEM. J. Am. Chem. Soc. 2010, 132, 7968-7975. [CrossRef]

70. Thiel, P.A.; Shen, M.; Liu, D.-J.; Evans, J.W. Coarsening of Two-Dimensional Nanoclusters on Metal Surfaces. J. Phys. Chem. C 2009, 113, 5047-5067. [CrossRef]

71. Jiran, E.; Thompson, C.V. Capillary instabilities in thin films. J. Electron. Mater. 1990, 19, 1153-1160. [CrossRef]

72. Jacquet, P.; Bouteille, B.; Dezert, R.; Lautru, J.; Podor, R.; Baron, A.; Teisseire, J.; Jupille, J.; Lazzari, R.; Gozhyk, I. Periodic Arrays of Diamond-Shaped Silver Nanoparticles: From Scalable Fabrication by Template-Assisted Solid-State Dewetting to Tunable Optical Properties. Adv. Funct. Mater. 2019, 29, 1901119. [CrossRef]

73. Powder Diffraction File, File No. 04-0783 (Cubic Structure of Ag). 1999. Available online: https:/ / ietresearch.onlinelibrary.wiley com/doi/10.1049/mnl.2017.0349 (accessed on 20 January 2022).

74. Harris, G.B.X. Quantitative measurement of preferred orientation in rolled uranium bars. Lond. Edinb. Dublin Philos. Mag. J. Sci. 1952, 43, 113-123. [CrossRef]

75. Consonni, V.; Rey, G.; Roussel, H.; Doisneau, B.; Blanquet, E.; Bellet, D. Preferential orientation of fluorine-doped SnO 2 thin films: The effects of growth temperature. Acta Mater. 2013, 61, 22-31. [CrossRef]

76. Dalchiele, E.A.; Giorgi, P.; Marotti, R.E.; Martín, F.; Ramos-Barrado, J.R.; Ayouci, R.; Leinen, D. Electrodeposition of ZnO thin films on n-Si(1 0 0). Sol. Energy Mater. Sol. Cells 2001, 70, 245-254. [CrossRef]

77. Riveros, G.; Ramírez, D.; Gau, D.L.; Hernández, L.; Häberle, P.; Marotti, R.E.; Romero, R.; Cuevas, A.; Martín, F.; Dalchiele, E.A. Electrodeposition of Single Phase SnS Thin Films: Effect of Electrolytic Bath Temperature on the Final Film Properties. J. Electrochem. Soc. 2019, 166, D44-D51. [CrossRef]

78. Hong, R.; Shao, W.; Ji, J.; Tao, C.; Zhang, D. Thermal annealing induced the tunable optical properties of silver thin films with linear variable thickness. Superlattices Microstruct. 2018, 118, 170-176. [CrossRef]

79. Patterson, A.L. The Scherrer Formula for X-ray Particle Size Determination. Phys. Rev. 1939, 56, 978-982. [CrossRef]

80. Scherrer, P. Nachrichten von der Gesellschaft der Wissenschaften zu Göttingen. Math. Kl. 1918, 2, 98-100.

81. Powder Diffraction File, File No. 41-1104 (Cubic Structure of $\mathrm{Ag}_{2} \mathrm{O}$ ) 1999. Available online: http:// publications.aston.ac.uk/id/ document/53505 (accessed on 20 January 2022).

82. Kuzma, A.; Weis, M.; Flickyngerova, S.; Jakabovic, J.; Satka, A.; Dobrocka, E.; Chlpik, J.; Cirak, J.; Donoval, M.; Telek, P.; et al. Influence of surface oxidation on plasmon resonance in monolayer of gold and silver nanoparticles. J. Appl. Phys. 2012, 112, 103531. [CrossRef]

83. Henry, C.R. Morphology of supported nanoparticles. Prog. Surf. Sci. 2005, 80, 92-116. [CrossRef]

84. Liang, C.; Huang, S.; Zhao, W.; Liu, W.; Chen, J.; Liu, H.; Tong, Y. Polyhedral $\mathrm{Fe}_{3} \mathrm{O}_{4}$ nanoparticles for lithium ion storage. New J. Chem. 2015, 39, 2651-2656. [CrossRef] 
85. González, A.L.; Noguez, C.; Beránek, J.; Barnard, A.S. Size, Shape, Stability, and Color of Plasmonic Silver Nanoparticles. J. Phys. Chem. C 2014, 118, 9128-9136. [CrossRef]

86. Sun, S.; Zhang, X.; Cui, J.; Yang, Q.; Liang, S. High-index faceted metal oxide micro-/nanostructures: A review on their characterization, synthesis and applications. Nanoscale 2019, 11, 15739-15762. [CrossRef] [PubMed]

87. Lv, J.; Lai, F.; Lin, L.; Lin, Y.; Huang, Z.; Chen, R. Thermal stability of Ag films in air prepared by thermal evaporation. Appl. Surf. Sci. 2007, 253, 7036-7040. [CrossRef]

88. Herley, P.J.; Prout, E.G. The Thermal Decomposition of Silver Oxide. J. Am. Chem. Soc. 1960, 82, 1540-1543. [CrossRef]

89. Schön, G.; Tummavuori, J.; Lindström, B.; Enzell, C.R.; Swahn, C.-G. ESCA Studies of Ag, $\mathrm{Ag}_{2} \mathrm{O}$ and AgO. Acta Chem. Scand. 1973, 27, 2623-2633. [CrossRef]

90. Moulder, J.F.; Stickle, W.F.; Sobol, W.M.; Bomben, K.D. Handbook of X-ray Photoelectron Spectroscopy; Perkin-Elmer Corporation, Physical Electronics Division: Eden Prairie, MN, USA, 1992.

91. Ferraria, A.M.; Carapeto, A.P.; do Rego, A.M.B. X-ray photoelectron spectroscopy: Silver salts revisited. Vacuum 2012, 86, 1988-1991. [CrossRef]

92. Hoflund, G.B.; Hazos, Z.F.; Salaita, G.N. Surface characterization study of Ag, $\mathrm{AgO}$, and $\mathrm{Ag}_{2} \mathrm{O}$ using X-ray photoelectron spectroscopy and electron energy-loss spectroscopy. Phys. Rev. B 2000, 62, 11126-11133. [CrossRef] 